Competition and Opportunistic Advice of Financial Analysts:

Theory and Evidence

By

Enrico Sette

DISCUSSION PAPER NO 592

DISCUSSION PAPER SERIES

June 2007

Enrico Sette is a final year PhD student at the LSE. Since July 2005, he has been an Economist in the research department of the Bank of Italy. His research interests are the theory of incentives and information applied to the analysis of financial institutions and contracts. Any opinions expressed here are those of the authors and not necessarily those of the FMG. The research findings reported in this paper are the result of the independent research of the authors and do not necessarily reflect the views of the LSE. 


\title{
Competition and Opportunistic Advice of Financial Analysts: Theory and Evidence
}

\author{
Enrico Sette* \\ London School of Economics and Bank of Italy
}

June 20, 2007

First draft June 2005. This version June 2007

\begin{abstract}
This work investigates both theoretically and empirically how the behaviour of financial analysts is affected by competition, measured as the strength of coverage of a stock from other analysts. The interaction among analysts and investors is modelled as a dynamic cheap talk game. The theoretical model shows that analysts having a conflict of interest with investors, report information truthfully with higher probability if other, "neutral", analysts report information on the same stock. This empirical prediction is tested on data about recommendations on IPOs. The main result is that analysts working for the lead underwriter of the IPO ("insiders") are more optimistic when there are no other analysts (not working for the lead underwriter, "outsiders") covering the stock. The data also show that insiders do not seem to use the information contained in outsiders recommendations. Finally, outsiders are not influenced by recommendations previously issued by insiders. These results also allow to discriminate between competing hypothesis brought forward to explain insider's overoptimism. The empirical evidence suggests that insider analysts overoptimism is induced by incentives rather than by a "psychological bias".
\end{abstract}

Keywords: Competition, Financial Analysts, IPOs, Recommendations.

JEL Classification codes: D40, D82, G24, L15

\section{Introduction and Motivation}

The recent scandals involving some of the major players on Wall Street cast dark shadows on the conduct of many financial analysts. The prestige and glamour surrounding the profession during

\footnotetext{
${ }^{*}$ Contacts: e.sette@lse.ac.uk. The previous versions of this paper circulated with the title "Opportunistic Advice of Financial Analysts: Theory and Evidence". I would like to thank my supervisors Antoine Faure-Grimaud and Hyun Shin for their helpful guidance. I also thank Rocco Macchiavello, Andrea Tiseno, Michela Verardo, Fabian Waldinger and seminar participants at the LSE, FMG, Econometric Society European Meeting held in August 2006 in Vienna, for their helpful comments. All errors are my own. The views expressed in this paper are my own and do not necessarily reflect those of the Bank of Italy.
} 
the 1990s, which has been dubbed the "Age of the analysts", has been dissipated. The public debate focussed on searching for the causes of the excessive optimism shown by analysts when producing their reports about companies, as well as for appropriate corrective action. The incentive system influencing the analysts has been considered a major suspect and was put under close scrutiny by policy makers in order to restore confidence in financial information. The industry responded by claiming that analysts overoptimism was not driven by distorted incentives but by psychological biases leading analysts to have too positive an impression of the stocks they followed ${ }^{1}$. Another hot issue in the debate is to what extent market forces help to soften the potential conflicts of interest between investors and analysts and consequently the desirability and the effects of regulatory intervention.

The growing interest in the behaviour of financial analysts prompted the appearance of many important papers investigating different dimensions of the topic. Some papers document bookrunner ${ }^{2}$ analyst overoptimism. Rajan and Servaes (1997) show that analysts forecasts of IPOs future earnings are overoptimistic and they are even more so for more underpriced IPOs and over longer time horizons. Michaely and Womack (1999) show that sell side analysts are systematically more optimistic than other analysts in their recommendations. Michaely and Womack (2004) review the literature and discuss the different theories brought forward to explain overoptimism from analysts affiliated with the bookrunner. In particular they stress two major hypotheses: the first, which I label the "opportunistic view" maintains that sell side analyst overoptimism is driven by incentives. The bookrunner profits by placing shares of the IPO on the market and from trading commissions. Therefore a positive recommendation boosts both channels. The latter hypothesis, which I label the "naive view", suggests that analysts following the company through the due diligence process become truly convinced of the superior quality of the firm just like parents see their kids under an especially positive light. Other papers point attention on the role of reputation and career concerns in influencing analyst behaviour. Hong and Kubik (2003) focus on analysts career concerns and discuss the effects of earnings forecast precision on job separation. They show that controlling for accuracy, analysts that tend to be more optimistic are more likely to experience favorable job separations. This evidence suggests that career concerns could be a driver for bookrunner analysts overoptimism. Jackson (2005) using Australian data, shows that there is a positive relationship between reputation and performance and also that more accurate analysts acquire a higher reputation. Fang and Yasuda (2005) document, on US data, that there is a positive relationship between reputation and forecast quality. They also show that the relative accuracy of more reputable analysts deteriorates during hot market periods when the gains from opportunistic behaviour are greatest. Ljungqvist, Marston and Wilhelm (2005) investigate whether analyst behaviour influences the likelihood of banks winning underwriting mandates. Their results suggest that optimistic behaviour does not increase the chances of winning a mandate. However,

\footnotetext{
${ }^{1}$ Blanes-i-Vidal (2004) reports that "...we have the employer of analysts, usually investment banks, who have claimed that analysts report their private beliefs truthfully, although it is possible that some of them may suffer from honest (i.e. irrational) optimism about the companies they cover..."

${ }^{2}$ The bookrunner is the lead underwriter of the IPO.
} 
they do find that analysts are more optimistic when the fees at stake are larger.

The existing literature provides a starting point for the present work: there is evidence of sell side analysts overoptimism and there is evidence that reputational concerns are important for analysts.

This work contributes to this debate investigating how the behaviour of financial analysts is affected by competition, captured by the strength of analyst coverage of each stock. The paper develops a theoretical model whose predictions are subjected to empirical test. The model shows that sell side analysts incentives to be overoptimistic are tempered by competition and reputational concerns. The model tries to capture the institutional features of the market for financial information in order to derive testable predictions. These predictions are then tested on a dataset of recommendations about IPOs over the period 1995 - 2002. Another important contribution is that the empirical methodology developed in the paper allows to distinguish between the opportunistic view and the naive view as explanations for the overoptimism of analysts working for the lead underwriter of the IPO.

The theoretical model formalizes the interaction among analysts and investors as a dynamic cheap talk game. This is related to the contributions of Sobel (1985), Benabou and Laroque (1992), Morris (2001). The main step ahead from these papers is that multiple sources of information are introduced and their influence studied in detail. The focus on the effects of competition is shared with Horner (2002). The main difference is that my paper deals with a cheap talk model and the uninformed party can be "served" by multiple informed ones.

From now on, for expositional clarity, analysts working for the lead underwriter of the IPO are dubbed "insiders" while analysts working for other broker houses are dubbed "outsiders".

To summarize, the paper addresses the following questions:

- Are insiders less optimistic when other outsiders issued (or are likely to issue) a recommendation on the same stock?

- Do insiders influence recommendations from outsiders? (in other terms: do outsiders appear to use the information contained in insiders recommendation when issuing their own recommendations)

- Are insiders more likely to issue an optimistic recommendation if they observed an optimistic recommendation from an outsider? (in other terms: do insiders appear to use the information contained in outsiders recommendation when issuing their own recommendations)

The first question investigates the effects of competition from outsiders on the behaviour of insiders. The model investigates the conditions ensuring that competition is beneficial for truthtelling incentives. The data document that insider analysts appear to be less optimistic when they observed a recommendation from outsiders, or when they expect them to issue a recommendation (these expectations are function of firm, industry and market characteristics). However, such behaviour is consistent both with the opportunistic and with the naive view. In fact, if insiders are psychologically biased 
in that they observe too positive a signal about the IPO, but are rational in updating their information, they will be less optimistic when observing the non biased signal contained in recommendations from outsider analysts. The second question investigates whether outsiders appear to update their information when observing a recommendation from an insider. The third question is crucial in discriminating between the opportunistic and the naive view: if insiders do not seem to be influenced by the information provided by outsiders, their overoptimism cannot be attributed to rational Bayesian updating, providing indirect evidence in favour of the opportunistic view.

The paper proceeds as follows: section 2 outlines the theoretical model, section 3 discusses the testable predictions, section 4 outlines the identification strategy, section 5 presents the dataset, section 6 describes the empirical results, section 7 contains robustness checks, section 8 discusses assumptions and results, section 9 concludes.

\section{A Model of Analyst Behaviour}

The interaction among analysts and investors is modelled as a dynamic cheap talk game: analysts privately observe the realization of a random variable that provides information about the quality of the firm, and send a recommendation to investors. The latter adjust their portfolios possibly using the information provided by analysts. Insider analysts have a conflict of interest: they would like to report favorable information, so as to induce investors to purchase the stock, even when they observe a negative signal, because they are incentivized to do so by their employer. Each analyst is characterized by a type (careerist, not careerist) which is constant over time and across firms, and a condition (insider, outsider) which is constant over time for a given firm. The type of analysts is modelled as follows: the careerist type is willing to enjoy the current profit as he cares both about his future reputation, and about conforming to the interests of the bank he works for. On the contrary, a non careerist type wishes to report the truth anyway, because of, say, strong moral characteristics that induce very large costs from behaving opportunistically. Notice that even a small fraction of such analysts is sufficient to generate the results. The market appreciates non careerist analysts because their incentives are aligned to those of investors.

Players: there are one insider (he), one outsider (he) and one investor (she).

Timing: Agents interact on an infinite horizon, repeating the same stage game (evaluation of an IPO and investment decision).The timing of the stage game is as follows:

1. Analysts receive a signal about the quality of the IPO and report it (issue a recommendation) immediately as soon as they observe it. Hence, no strategic delay is allowed. The outsider analyst might not cover the stock, in that case they receive no information and issue no recommendation. The insider does not know whether an outsider covers the stock. Recommendations are publicly observed. 
2. The investor adjusts her portfolio each time she observes a recommendation, provided the recommendation has enough credibility (notice that it is optimal for her to do so as I am assuming no adjustment costs).

3. Payoffs are realized and all players observe whether the recommendation was correct. Therefore reputation of an analyst is public information.

Information Structure: agents can be of two types, careerist and not careerist. The prior probability of the latter event is $\lambda$. An analyst's type is drawn at the very beginning of the game and is private information. The investor and the other analyst share the same beliefs about an analyst's type. Analysts also privately observe a signal $s$ about the realization of a binary random variable $\Theta=\{L, H\}$ representing the quality of the firm. The precision of the signal depends upon whether the analyst is an insider: insiders get more informative signals than outsiders. Formally,

$$
\begin{aligned}
& \operatorname{Pr}(\theta=Y \mid s=Y, \text { Insider })=a \\
& \operatorname{Pr}(\theta=Y \mid s=Y, \text { Outsider })=b
\end{aligned}, Y=L, H, \text { where } a>b>\frac{1}{2}
$$

ensures that insider agents get a more informative signal than outsiders. The signal of the insider is independent from those of the outsiders. This assumption could be relaxed, but it is to be noticed that the independent signal case implies the influence of outsiders on insider's behaviour is the weakest. If signals are not independent, recommendations of outsiders provide information about what the insider observed and thus about his type. Assuming independent signals implies that the presence of other senders only influences the chances the insider enjoys current profit if he lies. Suppose the insider reports that he observed $s=H$. He might have really observed this signal, but might also have observed $s=L$ and decide to take the benefits arising from inducing the investor to choose the action that increase current payoff (buy).

Contracts: monetary transfers contingent on the correctness of the recommendation are not feasible.

Analyst Strategies: analyst's actions in each period are $r: S \rightarrow R$; where $r$ is a mapping from the set of signals $S$ to the set of recommendations $R$. Attention is limited to Markovian strategies, i.e. strategies that depend upon history at time $t-1$ only. Strategies are probabilities of truthful reporting $q_{t}^{i, j}$, where $i$ denotes an agent type, $j$ denotes the state observed, and $t$ the time period.

Analyst Payoffs: the payoff of analysts is comprised of a wage which is increasing in his reputation and, when he is an insider, of a term which depends upon his ability to induce investors to purchase shares of the IPO. An outsider can have a payoff term that depends upon the probability of getting future business with the company. Formally, in the case of a careerist insider, current payoff is $U()=w\left(\lambda_{t-1}\right)+g(\Omega)$ where $w$ is a wage increasing in the reputation of the analyst for being non careerist (the intuition is that these are the analysts most valued by investors, though not necessarily 
by investment banks ${ }^{3}$. The assumption is motivated by the fact that analysts are nominated in the All American League by institutional investors and there is evidence that such analysts earn higher wages. The term $g$ represents the payoff from inducing investors to purchase the stock. $\Omega$ represents the beliefs of the insider about the likelihood the outsider will be issuing a recommendation. The function $U$ is continuous and maps $\mathbb{R}$ into $\mathbb{R}$. Non careerist insiders payoff features a cost of lying, so that $U()=w\left(\lambda_{t-1}\right)+g(\Omega)-M(1-q)$ and $M$ is so high that they will always find it optimal to set $q=1$, and are committed types. Careerist outsiders have a payoff $U()=w\left(\lambda_{t-1}\right)+I * \tau$ where $\tau$ is the gain from issuing a favorable report about the company in terms of greater chances of getting future business with the same company or with others, and $I$ is an indicator function taking the value 1 when outsiders get a short run gain by misreporting information, and 0 otherwise. In the latter case, as they do not gain anything by misreporting, they will be indifferent whether to report information truthfully or not, and I assume they will report their information at face value. Notice that such gains are independent on the behaviour of investors because the outsider is not going to gain by how successful the current IPO turns out to be. The possible gains are in terms of future business with the company and for that it is sufficient that a positive report is issued. Non careerist outsiders have a moral cost by lying so that they always report the truth. Finally, to ease the analysis, it is assumed that insiders face the risk of getting a punishment from their company if they are discovered reporting low prospects after having observed good prospects. The company can go to court and bring verifiable evidence. Such punishment is large enough so that insiders always report the truth if they observe a good signal (notice that this might not be necessarily the case, in equilibrium, for careerist insiders ${ }^{4}$ ). Therefore it follows that

$$
\begin{aligned}
& q_{t}^{N C, H}=1 \\
& q_{t}^{N C, L}=1 \\
& q_{t}^{C, H}=1
\end{aligned}
$$

where $N C$ refers to non careerist and $C$ to careerist. Hence, non careerist agents always report truthfully, while careerist agents always report truthfully if they observe the firm prospects are good. It remains to determine $q_{t}^{C, L}$, the probability a careerist analyst reports the truth when he observes the firm has bad prospects, and this will be determined in equilibrium. To ease notation, from now on, $q_{t}^{C, L}=q_{t}$.

Investor Payoff: The investor gets a payoff of $\Pi(\pi(\alpha))$ if she makes the right decision (i.e. sell when $Y=L$ and buy when $Y=H)$ and $\Pi(-\pi(\alpha))$ otherwise, where $\Pi: \mathbb{R} \rightarrow \mathbb{R}$, is continuous and

\footnotetext{
${ }^{3}$ Therefore investment banks are forced to link wage to the chances the analyst is non careerist because such analysts increase the appeal of the bank to investors, even if banks would prefer careerist types. The wage function could also include a component linked to the chances of internal career (which could then be decreasing in the probability the analyst is non careerist) without altering the basic insight of the model. However, if the internal career motive becomes too strong, insiders will have stronger incentives to misreport and in equilibrium their credibility could even be compromised.

${ }^{4}$ This follows because if in equilibrium careerist types find it optimal to report optimistically when the state is low with relatively large probability, they can also have incentives to "pool" with non careerist and report a low state more often than what own information would dictate. This is essentially the "political correctness" effect highlighted in Morris (2001).
} 
differentiable at least twice. Moreover, $\Pi_{\pi}>0, \Pi_{\pi \pi}<0$ (so as to ensure a unique interior solution), $\pi_{\alpha}>0$, where $\alpha$ is the quantity of shares traded. The investor adjusts her portfolio by varying $\alpha$ (for example, buying or selling) as a function of the likelihood the messages received are correct. An insider analyst is credible as long as $\lambda_{t} a+\left(1-\lambda_{t}\right)\left[a+(1-a)\left(1-q_{t}\right)\right]>\frac{1}{2}$. If this is not verified, the investor ignores the recommendation from the insider. When recommendations are credible, if only the message of the insider is available, the probability that buy is the true state conditional on a buy recommendation from the insider is given by

$$
\begin{aligned}
p= & \frac{\lambda_{t} a+\left(1-\lambda_{t}\right)\left[a+(1-a)\left(1-q_{t}\right)\right]}{\lambda_{t} a+\left(1-\lambda_{t}\right)\left[a+(1-a)\left(1-q_{t}\right)\right]+\lambda_{t}(1-a)+(1-\lambda)\left[(1-a)+a\left(1-q_{t}\right)\right]}= \\
& \frac{\lambda_{t} a+\left(1-\lambda_{t}\right)\left[a+(1-a)\left(1-q_{t}\right)\right]}{1+\left(1-\lambda_{t}\right)\left(1-q_{t}\right)}
\end{aligned}
$$

and the investor sets the optimal $\alpha$ as the solution of the program

$$
\left.\operatorname{Max}_{\alpha} p \Pi(\pi)+(1-p) \Pi(-\pi)\right)
$$

It is easy to see that $\alpha$ is increasing in $p$, which in turn increases in $q$. In fact the first order condition yields

$$
\frac{\partial \pi}{\partial \alpha}\left[p \Pi_{\pi}(\pi(\alpha))-(1-p) \Pi_{\pi}(-\pi(\alpha))\right]=0
$$

which reduces to

$$
p \Pi_{\pi}(\pi(\alpha))-(1-p) \Pi_{\pi}(-\pi(\alpha))=0
$$

and the implicit function theorem yields

$$
\frac{d \alpha}{d p}=-\frac{\Pi_{\pi}(\pi(\alpha))+\Pi_{\pi}(-\pi(\alpha))}{\left[p \Pi_{\pi \pi}(\pi(\alpha))+(1-p) \Pi_{\pi \pi}(-\pi(\alpha))\right] \pi_{\alpha}}
$$

which is positive as $\Pi_{\pi \pi}<0$. Notice that a bad signal will be taken at face value because careerist types never report a bad signal when observing a good signal as they could be punished by their employer. Therefore, following a sell report from the insider, $\alpha$ is set independently of $\lambda$, the probability the insider is non careerist ${ }^{5}$. This implies that $p=a$ is constant and $\alpha$ is set optimally independently of the analyst reputation.

For the moment, to simplify the exposition, it is assumed that $I=0$, so that the outsider does not gain anything by issuing a favorable recommendation, and therefore reports the information he observes. Notice that in such a case he will not use the informational content of recommendations that the insider might have issued earlier. Hence, if the investor also observes the message of the outsider,

\footnotetext{
${ }^{5}$ Allowing insiders to strategically report a bad signal when observing a good one, an effect similar to Morris (2001), would imply that the more reputable the insider, the more it hurts him to issue a bad signal as in that case $\frac{\partial \alpha}{\partial p}<0$. This is not the case here as a bad report surely means the insider observed a bad report and the probability the signal is correct is just $a$.
} 
the probability that buy is the correct action is represented by:

$$
p_{o}^{b, b}=\operatorname{Pr} o b(b u \mathrm{y} \mid b u \mathrm{y}, b u \mathrm{y})=\frac{b p}{b p+(1-b)(1-p)}
$$

where the notation indicates that a message from the outsider has also been issued, and that the message was a buy. As $p_{o}^{b, b}>p$, a buy message from an insider is reinforced by a buy message from the outsider. On the contrary, a sell message from an outsider reduces the probability the insider message was true: in fact, the probability that buy is the true state when the investor observes a buy message from an insider and a sell message from the outsider, becomes

$$
p_{o}^{b, s}=\operatorname{Pr} o b(b u \mathrm{y} \mid b u \mathrm{y}, \text { sell })=\frac{(1-b) p}{(1-b) p+b(1-p)}
$$

it is easy to see that $p_{o}^{b, s}<p$, so that now the investor will buy less shares of the company. Notice that if the probability the insider is non careerist is not large enough to ensure his recommendation is credible, then the message of the insider will be ignored and the only equilibrium involves babbling from the insider. On the contrary, when his messages are credible, then even if the message from an outsider is more credible, the investor will use all information to update her beliefs about the true quality of the company.

Beliefs: The analysis is still assuming that $I=0$ so that outsiders report information truthfully. Then, there is no updating on the type of the outsider. The market updates the reputation of an insider analyst for being non careerist according to Bayes rule, so that:

$$
\begin{aligned}
& \operatorname{Pr}(\text { non careerist } \mid \text { Sell }, \text { True })=\lambda_{t+1}^{S,+}=\frac{\lambda_{t}}{\lambda_{t}+\left(1-\lambda_{t}\right) q_{t}} \\
& \operatorname{Pr}(\text { non careerist } \mid \text { Sell }, \text { Wrong })=\lambda_{t+1}^{S,-}=\frac{\lambda_{t}}{\lambda_{t}+\left(1-\lambda_{t}\right) q_{t}} \\
& \operatorname{Pr}(\text { non careerist } \mid \text { Buy }, \text { True })=\lambda^{B,+}=\frac{a \lambda_{t}}{a \lambda_{t}+\left(1-\lambda_{t}\right)\left[a+(1-a)\left(1-q_{t}\right)\right]} \\
& \operatorname{Pr}(\text { non careerist } \mid \text { Buy }, \text { Wrong })=\lambda^{B,-}=\frac{(1-a) \lambda_{t}}{(1-a) \lambda_{t}+\left(1-\lambda_{t}\right)\left[(1-a)+a\left(1-q_{t}\right)\right]}
\end{aligned}
$$

It is useful to state a preliminary result.

Remark 1 A careerist insider never reports information truthfully with probability 1.

In fact in such a case, $\lambda_{t+1}^{S,+}=\lambda_{t+1}^{S,-}=\lambda_{t+1}^{B,+}=\lambda_{t+1}^{B,-}=\lambda_{t}$. Then, there is no reputational gain from reporting the truth, and thus lying is always optimal. This, however, contradicts the fact that $q=1$.

Equilibrium: the equilibrium concept is Markov Perfect Equilibrium. There always exists an equilibrium in which the investor discards recommendations, and analysts babble. Instead the focus here will be on equilibria with information transmission. In such equilibria the investor uses the information contained in recommendations, as long as analysts have enough credibility. 
The equilibrium is a set of beliefs $\Lambda$ about the insider analyst type, probability of truthtelling $0 \leq q_{t}<1$ and an optimal investment strategy $\alpha$ for the investor so that

$$
\alpha \in \arg \max E \Pi
$$

the insider behaves optimally and beliefs are confirmed in equilibrium and evolve according to Bayes rule. The payoff of the insider from reporting the truth is

$$
V_{T}=E(\alpha \mid s, \Omega) g+\delta\left[a W\left(\lambda^{S,+}\right)+(1-a) W\left(\lambda^{S,-}\right)\right]
$$

while that from lying is

$$
V_{L}=E(\alpha \mid b, \Omega) g+\delta\left[a W\left(\lambda^{B,-}\right)+(1-a) W\left(\lambda^{B,+}\right)\right]
$$

and the insider decides whether to lie or to randomize ${ }^{6}$, so that

$$
V_{T} \leq V_{L}
$$

In both expressions, $W($.$) is the continuation value. This formulation implies that the payoff of the$ insider depends upon the effectiveness of his recommendation: if the investor has more trust in the analyst, then $\alpha$ will be larger and the current gain amplified. The term $E(\alpha \mid j, \Omega)$, where $j=s, b$, represents the expected probability that the outsider issues a recommendation on the company, based upon company observable characteristics, such as industry, size and upon how hot the IPO market is and upon the general economic conditions which can be captured by a time variable. All these characteristics are included in $\Omega$. The expectation is conditional upon whether the recommendation issued by the insider was a buy or a sell, and of course $E(\alpha \mid b, \Omega)>E(\alpha \mid s, \Omega)$. The analysis concentrates on equilibria associated with value functions $W$ non decreasing and continuous in own reputation $\lambda^{7}$. It is still to be proved that the equilibrium is unique, that is, there is a unique value function $W$, solving the dynamic problem of the insider, and that the equilibrium probability of truthtelling $q^{*}$, is unique. This task can be accomplished by applying standard recursive techniques.

Proposition 2 The game has a unique equilibrium probability of truthtelling $q_{t}$.

Proof. It will be proved firstly that there exists a unique $q$ that solves the equation $V_{T}-V_{L}=0$ for every $\lambda$ and $W$. To this end, define a function

$$
\begin{aligned}
S(q, \lambda, W) & =V_{T}-V_{L}=E(\alpha \mid s, \Omega) g+\delta\left[a W\left(\lambda^{S,+}\right)+(1-a) W\left(\lambda^{S,-}\right)\right] \\
-E(\alpha & \mid \quad b, \Omega) g-\delta\left[a W\left(\lambda^{B,-}\right)+(1-a) W\left(\lambda^{B,+}\right)\right]
\end{aligned}
$$

\footnotetext{
${ }^{6}$ Remark 1 shows that $q=1$ (implying $V_{T}>V_{L}$ ) cannot occur in equilibrium.

${ }^{7}$ There could be equilibria with $W$ decreasing in $\lambda$. Such equilibria are not very intuitive though, and can be discarded.
} 
The function $S$ is continuous: this follows by continuity of $W, \lambda$ and $\alpha$. The function $S$ is monotonically decreasing in $q$. This follows because when $q$ raises, the first term decreases and the second term increases as $\frac{\partial \lambda^{S,+}}{\partial q}<0, \frac{\partial \lambda^{S,-}}{\partial q}<0, \frac{\partial \lambda^{B,-}}{\partial q}>0, \frac{\partial \lambda^{B,+}}{\partial q}>0$. Furthermore, $\frac{\partial E(\alpha \mid b, \Omega)}{\partial q}>0$. as $\frac{\partial \alpha}{\partial p}>0$ and the derivative $\frac{\partial p}{\partial q}$ is $\frac{\left(1-\lambda_{t}\right)(2 a-1)}{\left[1+\left(1-\lambda_{t}\right)\left(1-q_{t}\right)\right]^{2}}>0$ as $a>\frac{1}{2}$; while $\frac{\delta E(\alpha \mid s, \Omega)}{\partial q}=0$ as a sell recommendation is taken at face value and is independent of $q$. Hence the term $E(\alpha)$ $s, \Omega) g-E(\alpha \mid b, \Omega) g$ is monotonically decreasing in $q$. Then, the assumption that only continuation values $W$ increasing in $\lambda$ are considered ensures monotonicity is verified. Thus the function $S$ attains its maximum when $q=0$ and its minimum when $q=1$. There are two cases: if $W(1)<[E(\alpha(0) \mid$ $b, \Omega)-E(\alpha(0) \mid s, \Omega)] g+\delta\left[a W\left(\frac{(1-a) \lambda_{t}}{(1-a) \lambda_{t}+\left(1-\lambda_{t}\right)}\right)\right]$, then $q=0$ is always optimal ${ }^{8}$, because in such a case, by increasing $q$, the left hand side $V_{T}$ will decrease further and the left hand side $V_{L}$ increase. If, on the contrary, $W(1)>[E(\alpha(0) \mid b, \Omega)-E(\alpha(0) \mid s, \Omega)] g+\delta\left[a W\left(\frac{(1-a) \lambda_{t}}{(1-a) \lambda_{t}+\left(1-\lambda_{t}\right)}\right)\right.$, as $S(1)<0$ there exists a unique $q^{*} \in(0,1)$ so that $S\left(q^{*}\right)=0$, and $V_{T}=V_{L}$.

This shows that for each $\lambda$ and continuation value $W$ there exists a unique $q$ that satisfies $V_{T}$ $\leq V_{L}$. Also notice that given the continuity of $S$, uniqueness of $q^{*}(\lambda, W)$ implies its continuity. The next step consists in proving that there exists a unique value function $W$ solving the program. To this end it will be proved that the function $T W(\lambda)=\max \left\{V_{T}(\lambda) ; V_{L}(\lambda)\right\}$ is a contraction, so that by invoking Blackwell Theorem it is possible to prove that the value function is unique. In equilibrium, either $q^{*}=0$ and then $V_{T}<V_{L}$, so that $\max \left\{V_{T} ; V_{L}\right\}=V_{L}$, or $q^{*} \in(0,1)$ and $V_{T}=V_{L}$, so that $\max \left\{V_{T} ; V_{L}\right\}=V_{T}=V_{L}=V$ Hence $T W(\lambda)=V_{L} 1_{q^{*}=0}+V 1_{q^{*} \in(0,1)}$. The function $T W(\lambda)$ is continuous by continuity of $q, \lambda$ and $W$. To prove monotonicity, note that when $q^{*} \in(0,1)$, the identity $V_{T}=V_{L}=V$ holds. Consider the couple $\left(\lambda_{1}, W_{1}\right) \geq\left(\lambda_{2}, W_{2}\right)$. Then, if the associated $q^{*}$ are such that $0<q_{1}^{*}<q_{2}^{*}$, one can exploit the fact that $V=V_{T}$ to show that $V\left(\lambda_{1}, W_{1}\right)>V\left(\lambda_{2}, W_{2}\right)$. On the contrary, if $q_{1}^{*}>q_{2}^{*}>0$, the fact that $V=V_{L}$ allows to prove that $V\left(\lambda_{1}, W_{1}\right)>V\left(\lambda_{2}, W_{2}\right)$. Finally, when $q_{1}^{*}=q_{2}^{*}=0, V=V_{L}$, and again it is easy to see that $V\left(\lambda_{1}, W_{1}\right)>V\left(\lambda_{2}, W_{2}\right)$. Thus the value function $V=\max \left\{V_{T}, V_{L}\right\}$ is monotonic. Discounting is satisfied as well, so that it is possible to invoke Blackwell Theorem to conclude that $T W$ is a contraction and admits a unique fixed point $W$. This, together with uniqueness of $q$ satisfying $V_{T} \leq V_{L}$, proves the equilibrium is unique.

The next step is to investigate what happens if $I=1$ so that careerist outsiders might want to mislead the investor in order to please the firm going public and raise the chances of getting future business. In such a case, a sell recommendation is taken at face value, while the probability a buy recommendation from an outsider is correct is given by $r=\frac{\lambda_{t} b+\left(1-\lambda_{t}\right)\left[b+(1-b)\left(1-z_{t}\right)\right]}{1+\left(1-\lambda_{t}\right)\left(1-z_{t}\right)}$ where $z_{t}$ is the probability a careerist outsider reports information truthfully. This expression is analogous to that for careerist insiders taking into account that the signal of the outsider is correct with probability $b$. When the investor observes a recommendation from the outsider after that of an insider she will

\footnotetext{
${ }^{8}$ Note that in this case, $\lambda^{+, S}=\lambda^{-, S}=1$
} 
update her beliefs in the obvious way and

$$
\widetilde{p}_{o}^{b, b}=\operatorname{Pr} o b(b u \mathrm{y} \mid b u \mathrm{y}, b u \mathrm{y})=\frac{r p}{r p+(1-r)(1-p)}
$$

and

$$
\widetilde{p}_{o}^{b, s}=\operatorname{Pr} o b(b u \mathrm{y} \mid b u \mathrm{y}, \text { sell })=\frac{(1-b) p}{(1-b) p+b(1-p)}
$$

where the latter expression follows because sell messages are taken at face value. In such a case the chances the message from the outsider is correct is given by $b$. The Markov Perfect Equilibrium will now be a set of beliefs $\Lambda$ about the insider and the outsider type, probability of truthtelling for careerist insiders $q_{t}$ and for careerist outsiders $z_{t}$, an optimal action $\alpha$ for the investor so that

$$
\alpha \in \arg \max E U
$$

and the careerist insider and careerist outsider optimally decide whether to randomise of lie. The proof for the existence of a unique equilibrium probability of truthtelling for the careerist insider and outsider is analogous to the previous case when the careerist outsider has no incentive to misreport, and is thus omitted.

Now, it is possible to analyse the effects of competition on truthtelling incentives. It will be firstly discussed the simpler case when $I=0$ and the outsider just reports his signal. The answer can be found by inspecting $E(\alpha \mid b, \Omega)$. As $\alpha$ is increasing in the probability $p$ that the buy message is correct given the available information, it is sufficient to focus on the latter probability. Hence the insider knows that $\alpha$ is larger, the larger $p$. Thus he picks his optimal policy as a function of $E(p \mid b, \Omega)$. The latter is equal to $\left.\gamma\left\{a\left[(1-b) p_{o}^{b, b}+b p_{o}^{b, s}\right]+(1-a)\left[b p_{o}^{b, b}+(1-b) p_{o}^{b, s}\right)\right]\right\}+(1-\gamma) p$ where $\gamma(\Omega)$ is the probability the outsider issues a recommendation on the company and it depends upon the vector $\Omega$ defined above. This follows because upon observing a low signal, the insider knows the outsider correctly observes a low signal with probability $a b$, thus issuing a sell recommendation, and inducing investor beliefs $p_{o}^{b, s}$ that the company has good prospects. With probability $a(1-b)$ the outsider observes a good report, thus recommending to buy, so that investor beliefs become $p_{o}^{b, b}$. The intuition for the rest of the expression should now be obvious.

The next proposition examines the effects of competition on the expected trading volume of the investor.

Proposition 3 The higher the chances the outsider issues a recommendation, the lower the expected $\alpha$ if the insider reports a buy recommendation. If the insider issues a sell recommendation, his expectations of $\alpha$ do not depend on the chances an outsider issues a recommendation.

Proof. The expected probability the buy message is correct if the outsider might issue a recommendation is given by: $\gamma\left[(a+b-2 a b) p_{o}^{b, b}+(2 a b+1-a-b) p_{o}^{b, s}\right]+(1-\gamma) p$. The derivative of this expression with respect to $\gamma$ is $p_{o}^{b, s}-p+(a+b-2 a b)\left(p_{o}^{b, b}-p_{o}^{b, s}\right)$. The derivative is negative as long 
as $b>\frac{1}{2}$ which is verified as the signal of the outsider is informative. Hence the more likely the outsider issues a recommendation, the less strongly the insider will be able to influence the investor with a buy message. A different reasoning applies if the insider reports a sell message. In such a case the expected probability buy is the right thing to do after the insider issued a sell recommendation is $\gamma\left[(a+b-2 a b) p_{o}^{s, b}+(2 a b+1-a-b) p_{o}^{s, s}\right]+(1-\gamma)(1-a)$. It is easy to see that now the derivative with respect to $\gamma$ is nil. This follows because the sell recommendation is taken at face value and considered as correct with probability $a$.

The intuition for this result is that in the case of a buy recommendation after observing a poor signal on the company, the insider knows the outsider is more likely to have observed a poor signal (even if signals are independent, they are not conditionally independent) and thus more likely to recommend to sell. Therefore, the larger the chances the outsider issues a recommendation, the larger the chances he issues a sell recommendation, inducing the investor to buy less shares of the IPO. This follows because $p \neq a$. On the contrary, if the insider issues a sell recommendation, then his expectation, today, of what the outsider reports, is just his signal. Therefore the degree of competition has no effect. The asymmetry between the buy and the sell recommendation comes from the fact that if the insider reports buy when observing sell, he attributes a larger probability to the event that the outsider observed poor prospects for the company. Therefore, it is more likely that he issues a sell recommendation, and this lowers the expectations about investor trading volume of the IPO.

\section{Proposition 4 Competition unambiguously improves truthtelling incentives.}

Proof. Competition is parameterized by the probability $\gamma$ that the outsider issues a recommendation. A greater $\gamma$ reduces $E(\alpha \mid b, \Omega)$ but has no effect on $E(\alpha \mid s, \Omega)$. In equilibrium it is true that

$$
\left.E(\alpha \mid s, \Omega) g+\delta\left[a W\left(\lambda^{S,+}\right)+(1-a) W\left(\lambda^{S,-}\right)\right]=E(\alpha \mid b, \Omega) g+\delta\left[a W\left(\lambda^{B,-}\right)+(1-a) W\left(\lambda^{B,+}\right)\right]\right\}
$$

or

$\left.[E(\alpha \mid b, \Omega)-E(\alpha \mid s, \Omega)] g=\delta\left[a W\left(\lambda^{S,+}\right)+(1-a) W\left(\lambda^{S,-}\right)\right]-\delta\left[a W\left(\lambda^{B,-}\right)+(1-a) W\left(\lambda^{B,+}\right)\right]\right\} \equiv \widetilde{V}_{\text {ins }}$

Hence, if the chances the outsider issues a recommendation raise, the left hand side is reduced. In equilibrium the right hand side has to go down in order to keep the insider indifferent between reporting the truth and lying. This implies that $q$ has to raise because $\delta\left[a W\left(\lambda^{S,+}\right)+(1-a) W\left(\lambda^{S,-}\right)\right]$ decrease in $q$, and $\delta\left[a W\left(\lambda^{B,-}\right)+(1-a) W\left(\lambda^{B,+}\right)\right]$ increase.

The intuition is that the presence of outsiders reduces the current gains by misreporting.

Notice that at first thought, the presence of outsiders could also affect share holdings after the insider reported a sell recommendation. That could reduce his current gains when reporting truthfully so much as to reduce truthtelling incentives. This intuition, however, is incorrect, because when the insider reports a sell recommendation, his expectation of the final beliefs of the investor are just his 
information as beliefs follow a martingale.

The model predicts that competition induces careerist insiders to report information truthfully more often, as the more competitive the market for financial information is, the larger the chances the outsider issues a recommendation. The result is derived under the assumption that outsiders do not derive any benefit by misreporting their information and thus act non strategically. If this is true, the outsider should not be influenced by the information contained in recommendations issued by insiders ${ }^{9}$. This is a further testable prediction of the model.

If careerist outsiders gain by issuing a favorable recommendation (in this case $I=1$ ), the effects of competition might be less clear. Now, if a careerist insider reports a buy signal, that might reduce the reputational cost for the careerist outsider to report a buy signal when observing low prospects for the company. This follows because if the insider recommendations have some credibility, a buy recommendation induces the outsider to update her beliefs about the true quality of the company.

Proposition 5 A careerist outsider observing a sell recommendation from an insider is more willing to misreport his information

Proof. The recommendation from the insider cannot make it less likely that a buy message is correct and thus reduces the reputational cost of a lie. In fact, notice that either the message of the insider has no credibility, and then has no effect, or it has some. In the latter case, if the outsider observed a low state his beliefs the true state is good are given by $\frac{p(1-b)}{p(1-b)+(1-p) b}$. Hence, the continuation value by lying is now given by $\frac{p(1-b)}{p(1-b)+(1-p) b} W\left(\lambda_{t+1}^{B,+}\right)+\left(1-\frac{p(1-b)}{p(1-b)+(1-p) b}\right) W\left(\lambda_{t+1}^{B,-}\right)$. The continuation value by reporting truthfully, is $W\left(\lambda_{t+1}^{s}\right)$. It is evident that a buy report from an insider lowers the reputational cost for a careerist outsider. This follows essentially by standard Bayesian updating. Notice that the current gains for a careerist outsider are represented by the probability of future business with the company going public, and thus are not dependent upon the effectiveness of the recommendation. This implies that they are not dependent on the degree of competition either.

Hence, a careerist insider might take into account the fact that the careerist outsider would be influenced by his report. In such a case competition could be harmful for truthtelling incentives. In order to establish whether that happens, it is useful to define the beliefs the careerist insider has about the probability that a careerist outsider will issue a buy recommendation in equilibrium. The latter is defined as $\omega\left(z_{t}\right)$ where the dependence on $z_{t}$, the equilibrium probability of truthtelling of a careerist outsider, indicates that what matters is the likelihood a careerist outsider issues a recommendation and that he behaves opportunistically. This probability should be part of the vector $\Omega$, but with

\footnotetext{
${ }^{9}$ Notice that this is not dependent upon the assumption that the signal of insider and that of outsider are independent. This follows because outsiders have no special interest in reporting truthfully as this provides no signal about their types. Outsiders just pool because careerist are indifferent between reporting the truth or lying and they will then prefer to pool. In such a case a wrong report will have no consequences on their reputation and this implies there is no interest in the informational content of insiders' recommendations.
} 
some abuse of notation I write $E\left(\alpha \mid j, \Omega, \omega\left(z_{t}\right)\right)$ where $j=b, s$; to stress that the expected gains from inducing the investor to purchase the stock also depend on the likelihood a careerist outsider issue a recommendation and lie. Notice that when the investor observes a recommendation, she knows the identity of the analyst issuing it and so can assess his reputation and weigh the credibility of the recommendation. Also notice that if the investor receives recommendations from a non credible outsider, and the insider fully anticipates this, then competition would have no effect on the behaviour of a careerist insider. The next proposition shows that in equilibrium the higher the chances the outsider issues a recommendation, the stronger truthtelling incentives.

Proposition 6 Competition cannot reduce truthtelling incentives, even if outsiders are strategic.

Proof. When outsiders are strategic a buy report from the insider raises the chances the outsider reports buy. The insider expectation (after reporting buy) of the probability the investor attaches to the IPO being good is:

$$
\begin{array}{r}
\gamma\left(1-\lambda_{t}\right)\left\{a\left[b\left(z_{t} \widetilde{p}_{o}^{b, s}+\left(1-z_{t}\right) \widetilde{p}_{o}^{b, b}\right)+(1-b) \widetilde{p}_{o}^{b, b}\right]+(1-a)\left[b \widetilde{p}_{o}^{b, b}+(1-b)\left(z_{t} \widetilde{p}_{o}^{b, s}+\left(1-z_{t}\right) \widetilde{p}_{o}^{b, b}\right)\right]\right\} \\
+\gamma\left\{\lambda_{t}\left[a\left(b \widetilde{p}_{o}^{b, s}+(1-b) \widetilde{p}_{o}^{b, b}\right)+(1-a)\left(b \widetilde{p}_{o}^{b, b}+(1-b) \widetilde{p}_{o}^{b, s}\right)\right]\right\} \equiv \gamma \omega\left(z_{t}\right)
\end{array}
$$

Therefore, if $\omega\left(z_{t}\right)>p$, the insider will have stronger incentives to lie when he expects there is more competition. The reason is that he expects the competing analyst shares the same incentives he has. The expression can be simplified, yielding

$$
\left[-z_{t}\left(1-\lambda_{t}\right)-\lambda_{t}\right](1-a-b+2 a b)\left(\widetilde{p}_{o}^{b, b}-\widetilde{p}_{o}^{b, s}\right)+\widetilde{p}_{o}^{b, b}-p>0
$$

However, if the outsider is credible (implying $\left.\lambda_{t} b+\left(1-\lambda_{t}\right)\left[b+(1-b)\left(1-z_{t}\right)\right]>\frac{1}{2}\right)$ the inequality cannot be satisfied. To see this, notice that the inequality is not satisfied either when $z_{t}=0$ or when $z_{t}=1$. Also, notice that the left hand side of the inequality is monotonically decreasing in $z_{t}$. Thus, competition cannot decrease truthtelling.

Thus, the model suggests that competition cannot reduce truthtelling incentives, independently on whether the outsider is strategic or not. The intuition for this result is that if the outsider is credible, then he is more likely to report information truthfully. Thus, in equilibrium, if the insider reported falsely a buy recommendation, he still expects the outsider is more likely to issue a sell recommendation. The only possibility is that the insider holds different beliefs from the investor about the type of the outsider (but this cannot happen in a Markov Perfect Equilibrium unless there is asymmetric information about the outsider type, or investors are not fully rational). Whether the latter happens, is in essence an empirical question.

It should also be borne in mind that a necessary (but not sufficient) condition for competition to be harmful for truthtelling incentives, is that outsiders are responsive to the insider recommendation. In particular, if the insider issues a buy recommendation, that should raise the chances the outsider 
issues a buy recommendation as well. This possibility will be investigated in the empirical section.

Until now it was assumed that the insider moves first. Removing this assumption does not harm the results. In fact, if both types of outsider have no incentive to misreport, then the model will be the same. If careerist outsiders had incentives to misreport, then they would decide their optimal action on the basis of the expectation the insider is careerist. A careerist outsider will have incentives to wait for the recommendation of the insider. On the other hand he might pool with non careerist and issue a recommendation before the insider to show the market he just cares about reporting his information. This is an interesting problem that, however, does not seem to alter the main mechanism highlighted in this paper.

The model would also yield predictions about the effect of reputation on incentives. For example, it is easy to see that as more information about an analyst type has been revealed, truthtelling incentives decrease. These aspects have not been emphasized in the discussion as the dataset does not allow to derive information about an analyst reputation.

Finally, an important assumption is that insiders have rational expectations about the likelihood outsiders issue recommendations. Therefore their behaviour reflects their correct forecast of the chances that some outsider will issue a recommendation on any given stock. However, insiders can make mistakes in assessing whether outsiders will issue a recommendation on the same stock.

In order to clarify the modelling strategy, the role of the main assumptions is summarized below:

- The greater precision of insider signals is introduced for the sake of realism, but plays no specific role for the results and could be dispensed with.

- The assumption that insiders do not issue a bad report when observing a good signal, determines the fact that the investor decision is not responsive to reputation when observing an unfavourable report because the signal is fully credible. The assumption considerably simplifies the analysis and its removal would modify the equilibrium of the game. However, the effects of competition highlighted in the model will still hold.

- The assumption about the timing of the game is needed to simplify the analysis. Without this assumption each analyst would choose optimally the timing to issue a recommendation. However, assuming this does not happen does not seem unrealistic as the data do not show any specific pattern. Furthermore, insider analysts cannot issue a recommendation earlier than 25 days from the IPO (40 days, since July 2002), so they have a relatively limited choice. Even allowing for strategic timing of information transmission, the basic insight about the role of competition would remain valid.

- The assumption that analysts always issue a recommendation when they receive information about a company is made to simplify the solution of the model. Allowing for strategic "silence" would not alter the basic insight of the model, it would add a further strategic choice to careerist insiders. This assumption, however, might have consequences for the empirical work: if analysts 
strategically choose to avoid sending a recommendation, the sample might be biased. This possibility is discussed further in section 7 .

- The model assumes that recommendations take a binary form. In practice, however, recommendations can be considered as partitions over the space of company states. The dataset used in the empirical analysis codifies recommendations in 5 intervals. The assumption of binary recommendation allows to improve the tractability of the analysis, without a great loss of generality.

- The model assumes there is one outsider only. This is not restrictive at all. It just helps reducing the computational and notational burden. In a more general set up, the insider and the outsiders will form beliefs about the likelihood other outsiders issue a recommendation, and how many of them are likely to do so. Hence the predictions of the model are suitable to be tested on data where more than one outsider issues a recommendation.

- The presence of only one insider is slightly more restrictive. The presence of multiple insiders complicates the analysis, but not the conclusion: in fact, insiders will now form beliefs about the chances other insiders issue a recommendation, but the intuition of the model will not be overturned.

- Career concerns in this model are not related to talent, but to some moral characteristics. A talent model, in which more talented analysts observe a more precise signal of the state of the world, can yield similar predictions. An important difference, however, will be in the behaviour of outsiders: the latter would always use the information contained in previous recommendations of insiders (as long as these are credible) because they will try to guess the true value of the firm using all available information.

A last point to notice is that in this model the degree of competition in future interactions with investors is unknown. Analysts do not know which IPO they will follow in the future, therefore a higher degree of competition on the current IPO does not increase the expected degree of competition in future IPOs (future stage games). Therefore competition has no effect on the value of future reputation. On the contrary, if a larger degree of competition on the current IPO implied a larger degree of competition in the future, then the value of building a reputation might decrease. Sette (2005) elaborates on this point in the context of organisational design.

\section{$3 \quad$ Testable Hypothesis}

The model predicts that competition is beneficial for truthtelling (insiders are less overoptimistic when some outsider issued a recommendation, or when they expect outsiders to do so).

Notice firstly, that insiders often do not know whether outsiders will issue a recommendation. They form expectations based upon variables such as the size of the IPO, the industry the firm operates 
in, how "hot" the market is. However, the fact insiders can make mistakes raises the difficulty to identify the effect of competition, because insiders might report the truth attaching a large probability outsiders issue a (truthful) recommendation, while this might not happen in the data.

Also, the model assumes that analysts are rational and driven by incentives. This is the view taken by the New York attorney - general, Eliot Spitzer, as well as by a large part of the press about the financial scandals of 2002-2003. An alternative hypothesis suggests that analysts are truly convinced of the superior quality of the stocks they follow, so that they receive an optimistically biased signal but do not realize it. Then there can be two possibilities: the first is that analysts are totally naive and ignore information that could be conveyed by recommendations issued by outsiders. In such a case, insider analysts should be more optimistic independently of whether they are the first analyst to issue a recommendation. The second possibility is that analysts, though optimistically biased, are rational in updating their beliefs. Then, if they are the first to issue a recommendation, they report the biased signal at face value. On the contrary, when an outsider issues a recommendation they update their signal and make a less optimistic, though positively biased, recommendation. Then the "naive view" predicts the same empirical behaviour as the "opportunistic view".

However, it is possible to distinguish between these hypotheses by testing whether insider analyst behaviour is affected by that of outsiders: if the insider is not more likely to issue an optimistic recommendation after observing an optimistic recommendation from outsiders, then there would be little evidence in favour of information updating taking place. Then, the opportunistic view would be consistent with the evidence, while the naive view would not.

To sum up, the following hypotheses will be brought to empirical test:

- H1: Insiders are less optimistic when it is more likely that there are outsiders issuing a recommendation about the stock, so that insiders face more competition.

If hypothesis $\mathrm{H} 1$ is correct, it might also be true that

- H2: Outsiders do not seem to react to the information contained in recommendations previously issued by insiders.

Then, in order to understand whether the behaviour of insiders is consistent with the "opportunistic view" rather than with the "naive view", it should be true that

- H3: The extent to which insiders issue an optimistic recommendation is not influenced by the observation of previous optimistic recommendations by outsiders.

The next section discusses the identification strategy where these aspects are developed and made operational, so as to define how to estimate the different hypotheses on the data. 


\section{Identification Strategy}

The identification strategy involves three steps. The first two steps are necessary to identify whether insider analysts behave differently when they issue a recommendation facing less competition. The third step is needed to shed light on the determinants of this behaviour distinguishing between the "opportunistic view" and the "naive view".

The first step is to define which agents have a stronger conflict of interest with investors. In order to achieve this goal, only IPO deals are included in the analysis. Limiting attention to recommendations about IPOs issued in the first days after the company went public allows to define clearly who is the insider. The main identifying assumption is that an insider will behave differently if he is the only analyst issuing a recommendation than if there are outsiders issuing a recommendation on the stock. Such a differential behaviour could be caused by the mechanism suggested by the theoretical model. A crucial condition is that once the appropriate controls are included in the regression, the fact that an insider is alone is not correlated with the intrinsic unobservable quality of the company. If this is not the case, results would be biased and inconsistent. In fact, this identification strategy relies upon an important assumption: firm quality is assumed to have the same distribution once industry and time periods are controlled for, so that the fact that insiders are "alone", thus facing less competition when they issue a recommendation, is independent of firm quality once a proxy for firm quality is included in the regression. This is not unreasonable, as firm specific quality depends mostly upon entrepreneurial quality once industry, business cycle effects and returns on the stock are controlled for. This point is further discussed in section 7. Finally, it is assumed that insiders have rational expectations on the likelihood outsiders issue a recommendation on each stock. This is important to ensure that "mistakes" in the recommendation due to a wrong assessment of firm characteristics are not correlated with the same firm characteristics included to control for the expected probability outsiders issue a recommendation.

The second step is to define the relevant event window: it is crucial to understand when a recommendation is issued by the insider with outsiders also covering the stock. Two approaches are employed in the analysis. The first considers a recommendation from the insider as being issued "alone" if either no other recommendation about the stock is issued, or if the insider is the first to issue a recommendation about the stock. This provides a clear way to identify whether the information provided by the insider can be contrasted with that provided by outsider analysts. The second approach states that an insider is issuing a recommendation "alone" when no other recommendation is being issued in the two previous days. Time windows of different width (up to four days) are used as robustness checks. A wider event window has the drawback that other informationally relevant events might be happening. I will also use other measures of competition: I will present regressions including the number of outsiders issuing a recommendation on the IPO as an alternative control for competitive pressure.

The third step is needed to establish whether an analyst updates his beliefs after observing a 
recommendation from other analysts (this could be due to rational Bayesian updating or to herd behaviour). This is crucial in order to understand whether the behaviour of insiders is driven by incentives or not. This task is accomplished by testing directly whether insiders seem to use the information contained in recommendations from outsiders (and vice versa). This is done by running a Probit regression to check whether the fact that outsiders issued a positive recommendation before the insider, raises the chances the latter issues a positive recommendation. A rejection of this hypothesis suggests insiders are optimistic independently of whether they observed an optimistic recommendation from outsiders. Of course, if the hypothesis is not rejected that could also be due to the intrinsic quality of the firm and the fact that signals are conditionally correlated.

\section{Description of Data}

Information about IPO deals is provided by Thomson One Banker. The dataset lists IPOs on the US market from 1995 to 2004 providing data about the identity of the bookrunner, the date of the IPO, the size of the issue, the offer price, the industry, the nationality of the company. There are 3886 IPOs in the dataset ${ }^{10}$. Data on analysts recommendations come from I/B/E/S. Recommendations are coded in a scale from 1 (the most favorable to the company, "the IPO is very good") to 5 (the least favorable to the company, "The IPO is very bad"). The database also provides information about the analyst issuing the recommendation, the date of the recommendation, the broker the analyst is working for. The two dataset are matched in order to identify who is the analyst issuing the recommendation and whether this analyst is working for the bookrunner and is thus an "insider", or not. The companies receiving at least one recommendation are 3081. The overall sample contains 80000 recommendations over the whole time span 1995 - 2004. I also include information on returns. These come from the CRSP database.

The main data issue is dealing with IPOs with more than one bookrunner. In such cases the game changes: one insider knows that there are chances that other insiders as well as outsiders issue a recommendation and this can modify his incentives. The strategy is to exclude the company when multiple insiders are issuing a recommendation in the same time window. The fact that brokers engaged in extensive M\&A activities is not an important problem for this work as the analysis is limited to the recommendations issued in the first days after the IPO.

Insiders are prevented to release recommendations about the company before the end of the "quiet period". Then, I consider all recommendations issued 20 days earlier and 20 days later than the end of the quiet period. This was set at 25 days until July 2002, and later extended to 40 days. For this reason, data on IPOs issued after the first quarter of 2002 have been excluded from the analysis ${ }^{11}$.

\footnotetext{
${ }^{10}$ This is consistent with the information provided by Jay Ritter on the number of IPOs per year in the US.

${ }^{11}$ These could be included adding other 20 days after the quiet period. Results are unchanged. However, recommendation issued 60 days after the IPO date might incorporate a great deal of new information and the comparison with the period when the quiet period ended on the 25th day after the IPO might be debatable.
} 
Therefore the sample includes recommendations issued 5 days after the IPO (end of the quiet period minus 20 days) and before 45 days after the IPO (end of the quiet period plus 20 days). This choice is motivated by the desire to have a clear definition of "competition", and by the desire to minimize distortions coming from the possibility that new information about the company becomes public in the meanwhile. A longer interval would add noise as it is more likely that new information gets revealed in the meanwhile. A shorter interval reduces the sample numerosity and makes inference difficult. Results are anyway robust to the choice of the length of the time interval around the end of the quiet period. Finally, I focus on US firms. This is because the "market" for news on international companies might be different. Anyway, results are not affected by the inclusion of non-US firms.

\subsection{Descriptive Statistics}

When the sample is restricted to recommendations issued not later than 45 days and not earlier than 5 days from the IPO for the time span 1995 - first quarter of 2002 (inclusive), the total number of observed recommendations drops to 4823, about 1987 firms, by 1601 analysts. When recommendations about firms having more than one bookrunner are excluded, the sample has 4556 recommendations about 1929 firms, by 1549 analysts. For some observations the analyst identity is not reported, though the bookrunner identity is. This occurs for 370 recommendations. When this happens, recommendations are excluded in order to be able to use information about analysts, both employing panel estimation and to adjust standard errors allowing for clustering at the analyst level. After this step, the sample features 4208 observations about 1884 firms by 1549 analysts. There are a few cases (34 observations) where an insider issues more than one recommendation in the 45 days sample. Sometimes this is due to a mistake in records (the same recommendation is recorded twice), in other cases it is a different recommendation issued a few days later. Typically this is more optimistic than the first and follows a more optimistic recommendation from an outsider. This is an interesting issue and it would deserve closer scrutiny as in 18 cases the second recommendation is more optimistic than the first, independently of the recommendations issued by outsiders, in 11 cases it is unchanged, even if outsiders report less optimistically in the meanwhile, and only in 4 cases (out of 34) the insider issues a worse recommendation. Unfortunately the limited number of observations available does not allow to provide hard evidence about this behaviour. These observations are excluded from the analysis, but the estimation has been performed also on the sample including such observations as a further robustness check and results hold.

The database also contains information on the type of shares issued. There are 15 different types of issues, as listed in Table I. 
Table I

\begin{tabular}{|l|lll||l|lll|}
\hline Type of shares issued & Freq & Percent & Cum & Type of shares issued & Freq & Percent & Cum \\
\hline Class A Shares & 138 & 6.48 & 6.48 & ADR & 1 & 0.05 & 7.70 \\
Class B Shares & 8 & 0.38 & 6.85 & ADS & 32 & 1.50 & 9.20 \\
Global Dep Shares & 1 & 0.05 & 6.90 & Common Shares & 1,892 & 88.83 & 98.03 \\
Income Dep Securities & 2 & 0.09 & 7.00 & Non-Voting Class B & 1 & 0.05 & 98.08 \\
Series B-1 & 1 & 0.05 & 7.04 & Ord/Common Shares & 11 & 0.52 & 98.59 \\
Sub Voting Sharess & 1 & 0.05 & 7.09 & Ordinary Shares & 24 & 1.13 & 99.72 \\
Limited Partnership Int. & 11 & 0.52 & 7.61 & Beneficial Interest & 6 & 0.28 & 100.00 \\
Trust Units & 1 & 0.05 & 7.65 & & & & \\
\hline
\end{tabular}

I am including in the analysis, ordinary (or common) shares, only. Comparing different financial instruments can be misleading as the degree of "competition" among analysts could differ for very specialized financial instruments. Also including issues of shares with limited (or extra) voting rights could affect the recommendation. Therefore the sample is limited to the IPOs classified as "Common shares", "Ord/Common Shs", "Ordinary Shares". In this case the dataset includes 3790 recommendation from 1428 analysts on 1717 firms. When I include information on returns, the sample size is marginally decreased. If returns in the three months following the IPO are included, then there are 3692 recommendations from 1390 analysts about 1649 IPOs and when returns are computed in the six months following the IPO, then there are 3660 recommendations from 1388 analysts about 1635 IPOs. The last refinement of the dataset concerns the exclusion of non-US firms ${ }^{12}$. Then, the analysis is performed on a sample made by 3614 recommendations from 1361 analysts about 1623 IPOs.

It is important to review the summary statistics of the sample.

The average recommendation is summarized in Table II-A.

\begin{tabular}{|lllll|}
\hline & Mean & Std. Dev. & Min & Max \\
All analysts excluding recommendations by multiple insiders & 1.566 & 0.5709 & 1 & 5 \\
Insiders & 1.521 & 0.5460 & 1 & 3 \\
Insider only when the insider is the first & 1.451 & 0.5400 & 1 & 3 \\
Insider only when no outsider issues a recommendation & 1.370 & 0.5010 & 1 & 3 \\
Insider only within two days time window & 1.460 & 0.5427 & 1 & 3 \\
\hline
\end{tabular}

A preliminary inspection of Table II-A suggests that insiders issue more optimistic recommendations than outsiders, and furthermore that insiders seem to be more optimistic when they face less competition.

\footnotetext{
${ }^{12}$ The inclusion of non-US firms does not affect the results.
} 
Table II-B summarizes the distribution of recommendations.

\begin{tabular}{|l|l|l|l|}
\hline Recc & All & Insiders & Outsiders \\
1 & 47.22 & 50.23 & 45.66 \\
2 & 49 & 47.35 & 49.86 \\
3 & 3.70 & 2.42 & 4.36 \\
4 & 0.05 & - & 0.08 \\
5 & 0.03 & - & 0.04 \\
\hline
\end{tabular}

About 50 percent of recommendations take the most positive value, 1, while the other half has a predominance of 2 . Hence recommendations could also be approximated by a binary variable, taking the value 1 or 0 .

It is also interesting to examine firm characteristics. Table III shows statistics about the size of the IPO. This is measured as the amount of proceedings from the IPO in million US dollars.

Table III - Size

\begin{tabular}{|l|l|l|l|}
\hline & all & insider first & insider and no outsiders \\
Mean & 3616 & 442 & 226 \\
Median & 156.11 & 72.11 & 51.69 \\
Std. Dev & 387.87 & 45.49 & 40.68 \\
Skewness & 6.32 & 7.97 & 46.19 \\
\hline
\end{tabular}

These statistics show that companies recommended only from insiders, or whose first recommendation is issued by an insider, are smaller on average. It seems obvious that outsiders are more likely to issue a recommendation about "larger" issues. This could constitute a problem if size is related to firm unobservable quality. On the contrary as long as size is a measure of firm visibility ${ }^{13}$, it will be a crucial factor in determining the incentives of outsiders to acquire information and issue a recommendation. Size is also measured as number of shares issued. The two measures are quite correlated (the coefficient of correlation is 0.81 ) and similarly distributed.

Table IV in the appendix summarizes the industry each firm pertains to, as recorded in the Thomson One Banker dataset. The table reports the 25 industries observed more often. Most firms operate in the IT sector (Software, IT Consulting \& Services, Semiconductors, etc.) reflecting the "Hi - Tech" boom of the nineties. The dataset provides two distinct definitions for industry, at different levels of aggregation. The most detailed of these ${ }^{14}$ is used in the regressions.

\section{Results}

I firstly test whether the predictions of the opportunistic view are consistent with the empirical behaviour of analysts. Then, I turn to discriminate between the opportunistic and the naive view.

\footnotetext{
${ }^{13}$ This expression refers to the degree investors are interested in getting information about the company.

${ }^{14}$ Similar to the SIC 3-digit classification, although not exactly coincident with the SIC classification system.
} 


\subsection{Testing the Opportunistic View}

The first step consists in testing the behaviour of insiders. The dependent variable is discrete and ordered. This suggests estimating a multinomial ordered Logit or Probit model. However, a linear model is more flexible as it allows an easier use of fixed or random effects estimation. Furthermore, the explanatory variables are mostly dummies and this makes the linear probability model a good approximation for the underlying model.

The fact that an insider faces less competition when issuing a recommendation should be influenced by the size of the issue, the time period, the specific situation of the firm, the industry, possibly the quality of the IPO. Then, the main regression takes the following form:

$$
\operatorname{recc}_{i, j, t}=\alpha+\beta_{0} \text { dumins }_{i, j, t}+\beta_{1} \text { insalone }_{i, j, t}+\gamma X_{j, t}+\varepsilon_{i, j, t}
$$

where $\operatorname{recc}_{i, j, t}$ is the recommendation about firm $j$ from analyst $i$ at time $t$, dumins $s_{i, j, t}$ is a dummy variable taking the value 1 when the recommendation from analyst $i$ about firm $j$ is issued by an insider, insalone $_{i, j, t}$ is a dummy variable taking the value 1 when the recommendation on firm $j$ is issued by an analyst $i$ being an insider "alone", thus facing less competition from outsiders, in the relevant time window, and $X_{j, t}$ is a matrix of controls including industry fixed effects, quarterly dummies to capture the effect of the business cycle, the size of the issue (measured as the proceeds amount of the issue ${ }^{15}$, the name of the variable is Size), the number of IPO per year (the name of the variable is Numipo), the S\&P 500 equally weighted index on the day of the recommendation ${ }^{16}$ (the name of the variable is S\&P 500 E.W.I.), and returns on the stock, as a control for the quality of the firm. I used the three, the six and the one year return from the issue date. Results are not affected by the choice of this time span. The three month return could be more directly affected by recommendations, while the one year return probably incorporates the influence of other events that were not included in the analyst information set at the time of the recommendation and could be very difficult to forecast. Therefore, I present results including the six-months returns as a control for quality ${ }^{17}$ (the name of the variable is Six Month Return). The set of controls $X$ aims at capturing the likelihood other analysts issue a recommendation and the factors that can affect the degree of optimism of the recommendation.

As mentioned above, a key issue is the criterion used to classify whether an insider faces less competition from outsider. Three criteria are used: the variable insalone will be labelled first when an insider is defined to face less competition if he is the first to issue a recommendation about the company, insstre if there is no recommendation about the company issued on the same date or in the two preceding days, and finally, onlyins if the insider is the only analyst issuing a recommendation

\footnotetext{
${ }^{15}$ Results are analogous if the number of shares issued is used as a measure of size.

${ }^{16}$ Source: Datastream.

${ }^{17}$ Another possibility is to include returns relative to industry performances, value weighted returns, or returns relative to the S\&P 500. Results are robust to these alternative choices.
} 
about the stock in the whole 45 days after the IPO date.

The error term $\varepsilon_{i, j, t}$ can take a two way component form, so that $\varepsilon_{i, j, t}=\zeta_{i}+\eta_{i, j, t}$ where $\zeta_{i}$ represents an analyst time invariant component. The crucial assumption for identification is that $E\left(d, \varepsilon_{i, j, t} \mid X\right)=0$ where $d=$ dumins, insalone, where insalone can be onlyins, first, insstre. It can be especially important to control for analyst fixed effects as firms can be allocated to analysts as a function of analyst characteristics. Another specification takes care of the fact that recommendations are discrete ordered variables, and the model is estimated as an ordered logit or probit. In such cases the model becomes

$$
\operatorname{Pr}\left(\text { recc }_{i, j, t}=k\right)=\Lambda\left(\beta_{0} \text { dumins }_{i, j, t}+\beta_{1} \text { insalone }_{i, j, t}+\gamma X_{j, t}+\varepsilon_{i, j, t}\right)
$$

for the logit, and

$$
\operatorname{Pr}\left(\text { recc }_{i, j, t}=k\right)=\Phi\left(\beta_{0} \text { dumins }_{i, j, t}+\beta_{1} \text { insalone }_{i, j, t}+\gamma X_{j, t}+\varepsilon_{i, j, t}\right)
$$

for the probit, where $k=1,2,3,4,5$ is the value of the recommendation. Finally, as recommendations issued by insiders only take values of 1,2 or 3 as summarized in Table II- $B$, it is possible to construct a binary variable taking the value 1 if the recommendations is the highest $($ recc $=1)$ and zero if the analyst has been less optimistic $(r e c c=2$ and $r e c c=3)$. The model then has the following form

$$
\operatorname{Pr}\left(\text { recc }_{i, j, t}=1\right)=\alpha+\beta_{0} \text { dumins }_{i, j, t}+\beta_{1} \text { insalone }_{i, j, t}+\gamma X_{j, t}+\varepsilon_{i, j, t}
$$

if the linear probability model is used,

$$
\begin{aligned}
& \operatorname{Pr}\left(\text { recc }_{i, j, t}=1\right)=\Lambda\left(\beta_{0} \text { dumins }_{i, j, t}+\beta_{1} \text { dinslone }_{i, j, t}+\gamma X_{j, t}+\varepsilon_{i, j, t}\right) \\
& \operatorname{Pr}\left(\text { recc }_{i, j, t}=1\right)=\Phi\left(\beta_{0} \text { dumins }_{i, j, t}+\beta_{1} \text { insalone }_{i, j, t}+\gamma X_{j, t}+\varepsilon_{i, j, t}\right)
\end{aligned}
$$

if, respectively, a logit or a probit specification is used. Finally, insalone $=$ first, onlyins, insstre depending on the definition used to identify an insider as being "alone" and thus facing less competition from outsiders.

The main hypothesis to be tested concerns the behaviour of analysts as a function of whether other analysts are transmitting information about the same company in a given time window. Starting from the linear model, one gets, $E$ (recc $\mid X$, insider $)=\alpha+\beta_{0}+\gamma X$ and $E($ recc $\mid X$, insider alone $)=$ $\alpha+\beta_{0}+\beta_{1}+\gamma X$. The main hypothesis to be tested is $\beta_{1}=0$ versus an alternative $\beta_{1} \neq 0$. The model would suggest furthermore that $\beta_{1}<0$, so that insiders are more optimistic when there is little coverage of the stock from outsiders. Then, when the ordered logit model is estimated one gets, $\operatorname{Pr}($ recc $=1$ | $X$, insider alone $)-\operatorname{Pr}($ recc $=1 \mid X$, insider $)=\beta_{1}$. Hence if $\beta_{1} \neq 0$, insiders would behave differently depending on whether there are other outsider analysts issuing a recommendation. Correspondingly, $\operatorname{Pr}($ recc $=5 \mid X$, insider alone $)-\operatorname{Pr}($ recc $=5 \mid X$, insider $)$ would be different from zero and its sign 
is the opposite of $\beta_{1}$. For intermediate outcomes, in order to test whether $\operatorname{Pr}($ recc $=k \mid X$, insider alone) $-\operatorname{Pr}($ recc $=k \mid X$, insider) (where $k=2,3,4)$ is positive, it is necessary to use the estimated threshold values. However, for the purpose of this work, it matters most to investigate whether insiders alone are more or less likely to issue the most optimistic recommendation. Finally, in the simple probit or logit model, where the dependent variable is the probability of observing a recommendation equal to 1 , the hypothesis is $\beta_{1} \neq 0$, to investigate whether $\operatorname{Pr}\left(\right.$ recc $_{i, j, t}=1 \mid X$, insalone $\left.=1\right)-\operatorname{Pr}\left(\right.$ recc $_{i, j, t}=$ $1 \mid X$, insalone $=0) \neq 0$, and a further hypothesis would be that $\beta_{1}>0$. Now, the sign of $\beta_{1}$ is positive because the dependent variable is the probability the recommendation is the most optimistic. Thus, $\beta_{1}>0$ means that when the insider issues the recommendation alone there is a larger probability of observing the most optimistic recommendation.

Table $\mathrm{V}$ in the appendix reports results for insalone $=$ first (an insider is identified as facing less competition if he is the first to issue a recommendation). The model is estimated with OLS, as an ordered logit, and with both analyst fixed and random effects ${ }^{18}$. The dummy is significant at the $10 \%$ level (p-value 0.07) when the model is estimated through OLS and maximum likelihood as an ordered logit. When analyst fixed effects are included, the dummy is still significant at the 10\% level, even if there is an average of about 2 recommendations per analyst. When the model is estimated with random effects, the dummy for the insider alone is significant at the $5 \%$ level. Of course this estimate could be inconsistent if $E\left(\zeta_{i}, X\right) \neq 0$, i.e. if the analyst fixed effect is correlated with the insider dummy, but an Hausman test does not reject the hypothesis that the random effect provides consistent estimates for the dummies for the insider facing less competition ${ }^{19}$. The dummy for being an insider is significant (at the 1\% level) only when analyst effects are taken into account. Moreover, the estimate of the coefficient for size is never significant, although it changes sign, becoming negative, when analyst fixed effects are included in which case it approaches the $10 \%$ significance level. It is also interesting to notice that the number of IPO in the year has a negative sign and it is significant when analysts fixed effects are included. Therefore, when the market is "hotter", controlling for analyst fixed effects, recommendations tend to be more optimistic. The S\&P 500 is positive and significant at the $10 \%$ level, except when analyst fixed effects are included. The positive sign seems to indicate that when the market raise, recommendations tend to be less optimistic. It is not easy to rationalize this fact. The six month return has the expected sign (negative, indicating that larger returns are associated with smaller, and thus more optimistic, recommendations) but it is not significant. This might be caused by the fact that returns at a relatively short horizon are a poor measure of the information received by analysts when issuing recommendations on $\operatorname{IPOs}^{20}$.

\footnotetext{
${ }^{18}$ Standard errors are estimated allowing for clustering at the analyst level except in the fixed and random effect cases. In the latter cases standard errors are consistently estimated provided the analyst effects are not time varying.

${ }^{19}$ Another point to be mentioned is that the panel is unbalanced. An analyst might disappear from the dataset both because he is fired, because is promoted or because resigns. I don't have such information. However it is not clear that the process determining whether an analyst is still in the sample is correlated to his degree of optimism as a function of the degree of competition from outsiders.

${ }^{20} \mathrm{Using}$ returns over longer horizons would add noise, as new information become available.
} 
Table VI reports the same analysis for the case insalone = insstre (the analyst is identified as facing less competition if there were no recommendations from outsiders or other insiders in the 2 days before). The coefficient for the dummy for the insider facing less competition is negative and significant at the 10\% level for the OLS estimation and at the 5\% when the model is specified as an ordered logit. When analyst fixed effects are introduced the dummy is negative but not significant, while when the model is estimated with random effects the dummy is negative and significant at the $10 \%$ level. Again when analyst effects are included the dummy for being an insider becomes significant. The other coefficients behave in the same way as in the set of regressions presented in Table V for the case insalone $=$ first.

Table VII reports results for the last definition used to identify an insider as issuing a recommendation facing less competition: the case insalone = onlyins (the insider is the only analyst to issue a recommendation on the stock). This is probably the most restrictive definition and opens the possibility that sample selection has the strongest influence. On the other hand this definition allows to better capture the situation when the insider analyst feels less competitive pressure (I am assuming she has rational expectations) and thus would, according to the model predictions, behave opportunistically. Results are stronger, as the dummy for insider alone is negative and significant at the $1 \%$ level when the model is estimated with OLS, or specified as an ordered logit. It is significant at the $5 \%$ level when estimated with analyst random effects and at the $10 \%$ level when analyst fixed effects are included. The other parameters show a behaviour analogous to the previous cases. Six month returns on the stock are negative as expected, but still not significant.

Finally, Table VIII reports the results of the regressions run considering recommendations as a binary variable, with 1 indicating that the most optimistic recommendation has been issued, for the case the insider faces less competition when is the first to issue a recommendation. Results for the other definitions are very similar. Again, the coefficient for the insider facing less competition has the expected sign (now positive as the dependent variable is now the probability of observing the most optimistic recommendation. Therefore a positive coefficient now indicates a more optimistic behaviour).The coefficient is significant at the $1 \%$ level when the model is estimated through random effects, and at the $5 \%$ level in all the other cases. The coefficient for size is not significant for all models. The same happens for the number of IPOs in the year. The coefficient on the six month return on the stock has the expected sign (now positive, indicating that a larger return is associated with a greater chances of observing the most optimistic recommendation), but it is not significant.

Table IX reports results from logit regressions with analyst fixed effects to take care of the potential effect of analyst unobserved heterogeneity in a properly specified binary choice model. Some observations are lost, as there are very few observations for some analysts that are all 0 or 1 and thus dropped by the estimation package. This reduces the sample size. However, the dummy for insider alone is significant at the $5 \%$ level when the insider is considered as facing less competition if he is the first to issue a recommendation, or if no recommendations from outsiders are observed in the previous three days, although in the latter case it is significant at the $10 \%$ level. On the contrary, it is not 
significant for "onlyins" (the coefficient has the predicted sign, however).

These results suggest that the number of outsiders, an explicit measure of coverage of the stock, should influence the behaviour of insiders. Including the number of outsiders who issued a recommendation in the 45 days time span in a regression might entail problems of endogeneity, as the number of outsiders might be larger if the quality of the company is better (but then, the bias should go in the opposite direction: insiders should observe better signals when in fact more outsiders issue a recommendation). If the insider has rational expectations, he will be able to forecast correctly the number of outsiders issuing a recommendation on the same company, and thus the degree of competition. Results suggest that, indeed, the degree of optimism of the insider falls, as the number of outsiders issuing a recommendation on the company grows. Table $\mathrm{X}$ shows the result of a regression for recommendations issued by insiders on the number of outsiders who issued a recommendation on the company plus the usual control. The number of outsiders has a positive and significant coefficient, indicating that the larger the number of outsiders, the higher, and thus the less optimistic, the recommendation. It is interesting to notice that now the coefficient for size is negative and significant, suggesting that insiders are more optimistic on larger firms, once controlling for the total number of outsiders. This is interesting as it seems to indicate that size embeds a larger chance outsiders issue a recommendation. Once this effect is netted out, size turns out to be significant and negative, indicating that larger com-

panies are more likely to receive positive recommendations by insiders. Table XI presents results of a probit regression for the probability the insider issues the most optimistic recommendation. Again, the number of analysts reduces the chances the insider is very optimistic (remember that a positive sign here points to a higher probability the insider issues a recommendation equal to 1). The other variables behave in the same way as in the linear regression presented in Table X.

Thus, this analysis suggests that insider analysts are less optimistic when the competitive pressure from outsider analysts is stronger.

\subsection{Discriminating between the Opportunistic and the Naive View: Testing for Bayesian Updating}

The results presented up to this point could have also been caused by "simple" rational Bayesian updating or even by herd behaviour: when insiders are the first to issue a recommendation they do not have any other information but their private signals, while if they can observe a report from an outsider, they might decide to use this information when issuing a recommendation on the company. Thus, it is important to understand whether Bayesian updating takes place, in order to distinguish the "opportunistic" versus the "naive" view to explain overoptimism. To this end, I will examine whether insiders are influenced by outsiders when issuing their recommendation. This is done by checking whether the chances the insider issues a positive recommendation increase after observing a positive recommendation from outsiders. In practice, I will both consider the average recommendation from outsiders, and the best recommendation. The average recommendation from outsiders issued before 
the insider is distributed as follows

\begin{tabular}{|l|lll||l|lll|}
\hline recc & obs & freq & cum & recc & obs & freq & cum \\
\hline 1 & 87 & 33.72 & 33.72 & 2.333 & 1 & 0.39 & 93.41 \\
1.333 & 2 & 0.78 & 34.50 & 2.5 & 7 & 2.71 & 96.12 \\
1.5 & 38 & 14.73 & 49.22 & 2.666 & 1 & 0.39 & 96.51 \\
1.666 & 5 & 1.94 & 51.16 & 3 & 9 & 3.49 & 100.00 \\
2 & 108 & 41.86 & 93.02 & & & & \\
\hline Total & & & & & 258 & & \\
\hline
\end{tabular}

where obs indicates the actual number of occurrences, freq the probability frequency, and cum the cumulative probability. It can be seen that half of the times the average recommendation is not below 1.5. Therefore I define a dummy variable taking the value 1 if the average recommendation is greater or equal than 1.5. This captures the cases where recommendations equal to 1 are not less than those larger than 1. The second regression uses the most optimistic recommendation issued by outsiders, and I define a dummy variable taking the value 1 when at least an outsider issued a 1 . This strategy is formalized as follows

$$
\operatorname{pr}\left(\text { recc }_{\text {ins }, i, t}=1\right)=\Phi\left(\alpha+\text { Boutopt }_{i}+\gamma X_{i, t}+\varepsilon_{i, t}\right)
$$

where recc $_{i n s, i, t}$ represents the recommendation issued by the insider on company $i$ at time $t$, outopt is a dummy taking the value 1 if either the average of outsider recommendations is larger than 1.5, or whether at least one outsider issued a 1 (the highest possible), and $X_{i, t}$ is a vector of controls including size, number of IPOs in the year, quarterly and industry dummies, the six month return on the stock, and the S\&P equally weighted index. The main hypothesis to be tested is whether $\beta \neq 0$, and in particular whether $\beta>0$. Table XII-A presents results for the sample including only recommendations issued in the three days prior to the date the insider issued his recommendation. As the sample is not very large, quarterly and industry dummies are excluded from the estimation. Results show clearly that outopt, the measure for outsider optimism, is not significant. Table XII-B presents results including all recommendations issued before the one issued by the insider. Of course there can be noise in these results, as new information about the company becomes available. Again there is no evidence the insider is more likely to issue the most optimistic recommendation following optimistic reports from outsiders. Similar results can be obtained if the regression includes all recommendations issued in the 10 or 5 days prior to the recommendation issued by the insider. Notice that finding a significant coefficient of the dummy for an optimistic report from outsiders would not signal that insiders use the information of outsiders, it could just be that the company is of intrinsically good quality. However, finding the coefficient is not significant is clearly inconsistent with the hypothesis that insiders update their information observing the information provided by outsiders. 
The same analysis is performed to investigate the behaviour of outsiders. The probit regression

$$
\operatorname{pr}\left(\operatorname{recc}_{\text {out }, i, t}=1\right)=\Phi\left(\alpha+\text { Binsopt }_{i}+\gamma X_{i, t}+\varepsilon_{i, t}\right)
$$

is run on the sample of recommendations issued by outsiders in the days after the insider recommendations. In the regression insopt is a dummy taking the value 1 if the insider issued the most optimistic recommendation. Results are reported in Table XIII and clearly indicate that the dummy is not significant: outsiders do not seem to use the information contained in insider's recommendations to update their beliefs about the company. This is interesting as insiders are likely to hold more precise information about the company. This result seems to suggest that outsiders do not regard the information provided by insiders as very credible ${ }^{21}$.

\subsection{Summary of Results}

The evidence provided so far suggests the following:

1. Insiders issue more optimistic recommendations when competition, measured in various ways referring to the extent of coverage from outsider analysts, is less intense.

2. Insiders do not seem to update their beliefs when observing outsiders recommendations, as the probability they issue the highest possible recommendation is not affected by whether they observed a positive recommendation by outsiders.

3. Outsiders do not use the informational content of insider's recommendations as they are not more optimistic after observing an optimistic recommendation from the insider.

These findings help to distinguish between competing hypotheses brought forward to explain insider analysts overoptimism. The first finding would be consistent both with an incentive based theory, and with an irrationality based theory where insiders are optimistically biased but update their information rationally, so that they learn about the true distribution of firm quality when observing recommendations from outsiders. The second finding would be consistent with an incentive based theory, but not with the "irrationality with learning" hypothesis. In the latter case, insiders should be more optimistic when observing an optimistic message and less optimistic otherwise. On the contrary, the fact that they tend to maintain the same degree of optimism independently of whether they observed positive recommendations from outsiders, suggests insiders behave opportunistically aiming at sustaining a positive perception of the quality of the IPO. The third finding, that outsiders do not seem to be influenced by an optimistic recommendation from the insider, signals that recommendations from insiders are not regarded as credible by outsiders.

\footnotetext{
${ }^{21}$ Of course there can be other explanations, such as the fact that outsiders want to impress the market through an anti-herding strategy.
} 
Thus far the analysis maintained the assumption that the degree of competition from outsiders, i.e. independent of intrinsic firm quality, once observable characteristics of the IPO are controlled for. The analysis also controlled for the influence of analyst fixed effects, and this seems to be sufficient to conclude that the dummy for the insider alone is exogenous conditional on firm characteristics and analyst identity. However, the next section explicitly addresses the possibility that some form of selection takes place, so that the degree of competition (stock coverage from outsider analysts) is lower exactly when the IPO is of better quality.

\section{Addressing Selection}

One potential problem of the analysis is the possible presence of selection bias: if it happens that insider analysts face less competition exactly when firms are better, then there would be no strategic behaviour from insiders who would just be reporting what they observe. There can be three answers to this important point. The first is that it would be hard to imagine that outsiders issue recommendations about worse firms: if they have more freedom about which firm to analyse, then it would be unlikely that they on average chose to cover the less promising firms. The second answer is that controlling for the number of IPOs in the year, industry and quarterly dummies, the six month return on the stock which is a proxy for quality, the size of the issue and analyst fixed effects, should be enough to control for the effect of selection. The third answer is to run regressions that can address the selection problem. I will firstly use an Heckman selection model, and then Instrumental Variables with the predicted probability the insider faces less competition (the insider is "alone") as an instrument. Both models use an exclusion restriction on the variable "size of the IPO". This variable typically used a control in regressions where the dependent variable is earnings forecast, or firm returns. I included it in the base model as a further control as I do not have access to many firm level characteristics. However, it is not theoretically clear why the size of the IPO should be included as an explanatory variable in a regression where the dependent variable is a recommendation which should represent a signal of firm quality. In other words, it is not obvious why the IPO size should affect its quality. This is especially true as I included a proxy for firm quality such as realized returns on the stock. The fact that size is not significant in the base regressions provides some support to this hypothesis. On the other hand, size is clearly a measure of firm visibility, and therefore of the likelihood outsiders will compete with the insider in providing information about the company. Thus, for these reasons, it seems that size can be part of a valid exclusion restriction and used to construct an instrument for the probability the insider faces less competition from outsiders.

A first regression models the probability the insider faces less competition using an Heckman selection model. The probability the insider issues a recommendation alone is modelled as follows

$$
\operatorname{Pr}\left(\text { Insalone }_{i, j, t}=1\right)=\Phi\left(\text { size }_{j}, X_{j, t}, \tau_{i, j, t}\right)
$$


where $\tau_{i, j, t}$ is a disturbance term, while the equation for the recommendation is as before

$$
\text { recc }_{i, j, t}=\alpha+\beta_{0} \text { dumins }_{j}+\beta_{1} \text { insalone }_{j, t}+\gamma X_{j, t}+\varepsilon_{i, j, t}
$$

where estimates of the latter equation would be inconsistent if $\operatorname{corr}\left(\tau_{i, j, t} ; \varepsilon_{i, j, t}\right) \neq 0$. The matrix of controls is analogous to that in the base model, I estimate the model using a two-step procedure, as this is more robust, although it would not be efficient if the two disturbances $\tau_{i, j, t}$ and $\varepsilon_{i, j, t}$ were jointly Normal. One exclusion restriction is imposed as size is used as explanatory variable for the probability the insider is alone, but it is excluded by the equation to explain the recommendation. Table XIV shows results. The dummy for the insider facing less competition is negative but not significant $(p-$ value at 0.14$)$ when insalone $=$ first. However, the disturbances seem not to be correlated, as the covariance lambda is not significantly different from zero: therefore the hypothesis that there is no selection cannot be rejected. The same happens when insalone = onlyins : the dummy for insider alone is not significant but the correlation between the disturbances is not significantly different from zero. When instead insalone = insstre, the coefficient is negative and significant at the $5 \%$ level. However, the covariance of the errors is again not significantly different from zero and the hypothesis that selection is not an issue cannot be rejected. Therefore, it might appear that the evidence that outsider analyst coverage induces a less optimistic behaviour on part of insider analysts is weakened by these results: the coefficient on the dummy for the insider facing less competition is significant only for one of the three definitions. However, there is little evidence for selection effect to matter once controls for returns and market conditions are included and there would be no need to run the Heckman selection model as the results presented in Tables 5 to 9 would provide consistent estimates of the parameters (at least the specification with analysts fixed effects).

Another approach consists in using instrumental variables. The positive side of this approach is that it poses less structure than the Heckman model. The instrument used is the predicted probability the insider is alone. This requires finding an appropriate exclusion restriction to estimate the model. As discussed above, size has no clear theoretical link with firm unobservable quality, while it is likely to be correlated with the degree of competition the insider faces on a given stock. The identification strategy thus uses the predicted probability the insider faces less competition as an instrument. Operationally, the first step consists in running a regression for $\operatorname{Pr}\left(\right.$ insalone $\left._{i, j, t}=1\right)=\Phi\left(\alpha+\rho X_{j, t}+\phi z_{j}\right)$, where $z_{j}$ is the size of firm $j$. Then the predicted probabilities $\operatorname{Pr}($ insalone $=1)$ are used as instruments for insalone in a 2 Stage Least Square regression, where the second stage is $\operatorname{recc}_{i, j, t}=\alpha+\beta_{0} d u m i n s_{j}+$ $\beta_{1} Z_{j, t}+\gamma X_{j, t}+\varepsilon_{i, j, t}$ and $Z_{j, t}$ is the first stage regression predicted insalone from the regression insalone $_{i, j, t}=\alpha+\eta \operatorname{Pr}\left(\right.$ insalone $\left._{i, j, t}=1\right)+\kappa X_{j, t}+\xi_{i, j, t}$. Wooldridge (2002) shows that this procedure allows to consistently estimate $\beta_{1}$. An important assumption for this approach to be valid is that $E$ (recc) is linear in the regressors. As recc is a discrete variable that will not hold in this case. However the linear probability model is a good approximation in this case and so this approach is not that bad in this situation. A nice feature of this identification strategy is that it is robust to mis- 
specification of the model for $\operatorname{Pr}($ first $=1)$. In fact, even if that is not a probit function, the estimates from the first step will be consistent, as argued in Wooldridge (2002). Results are summarized in Table XV: the dummy for insider facing less competition is negative and significant for both the case of insalone $=$ first and the case insalone $=$ onlyins. It is negative and barely significant for the case insalone $=$ insstre as the $p$-value on the coefficient is 0.106. On the contrary the behaviour of the dummy for insiders changes: the sign of the coefficient is now positive, indicating that insiders are more optimistic than the baseline situation (average outsider recommendation) when they are not alone. However it is never significantly different from zero. The number of IPOs per year is negative and significant, suggesting that the larger the number of IPOs, the more recommendations are positive. This can be caused by many effects: it could be that best firms tend to wait periods of "boom" to go public, or it could be that analysts tend to be more optimistic in periods when the market is "hot" as they know it is likely that all stocks will grow for a while and thus they can inflate more safely their recommendations.

\section{Discussion}

The evidence provided suggests that insider analysts behave differently according to whether there are other analysts providing information about a firm. This could be due to opportunistic behaviour, to Bayesian updating, or to sample selection. The latter can be excluded in light of the evidence provided by the selection and the I.V. regressions and by the set of controls included in the "standard" regressions. Thus it does not seem that insider analysts issue a recommendation facing less competition when companies are of higher quality. Bayesian updating is inconsistent with the evidence provided in section 5.3. Then opportunistic behaviour remains as the only explanation consistent with the empirical evidence.

An important implication of these results is that the "psychological" explanation for insider overoptimism is inconsistent with the evidence documented in this paper. On the contrary, the empirical evidence is consistent with the "opportunistic view" for analyst overoptimism. This conclusion has important policy implications: if insiders overoptimism was caused by a psychological bias, changing insiders incentives might have a limited effect on the information they provide. On the contrary, if their behaviour is driven by existing incentives, then that should be the focus of policy makers.

It is useful to discuss further the possible role of selection by thinking about what the results are suggesting. If insiders are more optimistic when no outsiders are issuing a recommendation because the firm is intrinsically better when they face less competition, then outsiders analysts tend to concentrate on firms that have worse perspectives ex-ante. This conclusion is difficult to defend: financial information can be thought of as an experience good. An investor appreciates the quality of an analyst recommendation if she invests in the company recommended. She would not do so if the recommendation is not very positive. It is difficult to think that investors follow a stock they did not purchase in order to evaluate whether the negative recommendation of the analyst was right. Thus, if anything, 
outsiders should, on average, cover a company with better ex-ante prospects. Then the fact the insider faces less competition would be negatively correlated with the quality of the company. In such a case the results of this paper would even more strongly suggest that insiders behave opportunistically and that competition has a beneficial role in disciplining insider analysts.

A last point concerns the decision to issue a recommendation: this has not been modelled formally, and it was assumed that insiders always issue a recommendation. However, this is not necessarily the case. It is not clear what the incentives of the insider are in such a situation: she might prefer to say nothing rather than issue a bad recommendation. Then, the market should discount this fact and interpret no recommendation as a bad recommendation, thus reducing the incentives to keep silent. Under an empirical point of view, this means there is no recommendation by insiders about the worst company. This can justify why insider recommendations are, on average, more optimistic than those of outsiders, but has no effect on the differential behaviour of insiders as a function of whether outsiders issue a recommendation. A possibility would be that insiders decide not to issue a recommendation because they know there will be an outsider around and the cost of lying, in terms of reputation, will be larger. In such a case, we would observe insiders issuing a recommendation when outsiders are likely to be around, for better companies, and the larger degree of optimism of insiders when they face less competition, would even be underestimated.

\section{Conclusion}

This paper develops a theoretical model to investigate whether the presence of less informed but unbiased agents can reduce opportunistic behaviour of more informed, but possibly biased agents (insiders). The theoretical model predicts that insiders should report information less optimistically when other unbiased, but less informed, agents issue a recommendation as well. This result is brought to data and tested on financial analysts recommendations on IPOs issued during the first 45 days from the date of the IPO. The main result is that analysts working for the bookrunner (insiders)

tend to be more optimistic when there is less coverage of the stock from outsider analysts. The paper employs three measures to identify when the insider is "monopolist" as coverage from outsiders is weaker: if she is the first analyst to issue a recommendation about the IPO, if no other analyst issued a recommendation on the same day and in the two previous days, if no other analyst issued a recommendation at all on the same company in the 45 days window. The empirical analysis shows that for all definitions, an insider facing less competition issues more optimistic recommendations. These results could not necessarily be driven by incentives, but might be generated by two factors. The first is rational Bayesian updating: insiders are optimistically biased but update their information if they can observe recommendations from outsiders. However regression analysis does not reject the hypothesis that the degree of overoptimism is independent of whether the insider observed information from outsiders, providing evidence against Bayesian updating. The second is selection: an insider could be facing less competition exactly when the firm is of better quality, so that the overoptimism is in fact just 
a truthful report about firms coming from a higher quality sample. Even though this seems unlikely to happen in practice, such concern can be addressed by estimating the model include appropriate controls, by estimating an Heckman model, and by using an instrumental variable framework. Results seem to be robust to these further checks.

Moreover the results of this paper allow to discriminate between the two major hypotheses the literature proposed to explain insider analysts overoptimism: the first, which I label the "opportunistic view" suggests that insiders are influenced by incentives, the second, the "naive view", suggests that analysts are affected by a cognitive bias that make them truly convinced about the superior quality of the firm they followed through the whole due diligence process. They might be less optimistic if they update their biased beliefs after observing the unbiased signals of outsiders. The fact that insiders are not more likely to issue a positive recommendation when they observe a positive recommendation from outsiders is inconsistent with this hypothesis. Hence, these results provide indirect evidence in favour of the hypothesis that insider analyst overoptimism is driven by incentives. The fact that insider analyst behaviour is shaped by incentives rather than by a psychological bias, is not only an academic result, but leads to important policy implications: if the naive view was correct, it would be advisable to appoint an analyst as responsible for the due diligence process, and a different one as responsible for providing information to the market after the IPO. That would create a duplication of effort but improve the quality of information. Measures aiming at reducing the extent to which analyst pay is linked to overall (and thus investment banking) performance will be useless. On the contrary, the opposite would be true if analysts are overoptimistic because of incentives as suggested by the results presented in this paper.

\section{References}

[1] Benabou, R. and Laroque, G. (1992). "Using Privileged Information to Manipulate Markets: Insiders, Gurus, and Credibility", Quarterly Journal of Economics, 107, 921-948

[2] Blanes-i-Vidal, J. (2004). "Credibility and Cheap Talk of Securities Analysts: Theory and Evidence", mimeo LSE

[3] Crawford, V. and Sobel, J. (1982). "Strategic Information Transmission", Econometrica, 50, 14311451

[4] Fang, L. and Yasuda, A. (2005). "The Dynamic Effect of Reputation on Conflict of Interest in Sell-side Research", mimeo Wharton School

[5] Hong, H. and Kubik, J. (2003). "Analyzing the Analysts: Career Concerns and Biased Earnings Forecasts", Journal of Finance, 58, 313 - 351

[6] Horner, J. (2002). "Reputation and Competition", American Economic Review, 92, 644-663 
[7] Jackson, A. (2005). "Trade Generation, Reputation, and Sell-side Analysts", Journal of Finance, $60,673-717$.

[8] Ljungqvist, A., Marston, F. and Wilhelm, W. (2005). "Competing for Securities Underwriting Mandates: Banking Relationships and Analyst Recommendations", Journal of Finance, forthcoming

[9] Michaely, R. and Womack, K. (1999). "Conflict of Interest and the Credibility of bookrunner Analyst Recommendations", Review of Financial Studies, 12, 653-686

[10] Michaely, R. and Womack, K. (2004). "Brokerage Recommendations: Stylized Characteristics, Market Responses, and Biases", forthcoming in Advances in Behavioral Finance II, R. Thaler Ed.

[11] Morris, S. (2001). "Political Correctness", Journal of Political Economy, 109, 231-265

[12] Rajan, R. and Servaes, H. (1997). "Analysts Following of Initial Public Offerings", Journal of Finance, 52, 507-529

[13] Sette, E. (2005). "Competing Influence", mimeo LSE

[14] Sobel, J. (1985). "A Theory of Credibility", Review of Economic Studies, 52, 557 - 573

[15] Wooldridge, J. (2002). "Econometric Analysis of Cross Section and Panel Data", MIT Press 


\section{Appendix - Tables}

Table IV - Distribution of firms by industry. Total number of firms: 1718

\begin{tabular}{|lll|}
\hline Industry & Number of obs. & Frequency \\
Software & 319 & 18.57 \\
IT Consulting\&Services & 140 & 8.15 \\
Professional Services & 119 & 6.93 \\
Healthcare Equipment\&Supplies & 111 & 6.46 \\
Semiconductors & 73 & 4.25 \\
Computers\&Peripherals & 64 & 3.73 \\
Telecommunications Equipment & 53 & 3.08 \\
Pharmaceuticals & 48 & 2.79 \\
Internet Software \& Services & 46 & 2.68 \\
Healthcare Providers \& Services(HMOs) & 41 & 2.39 \\
Biotechnology & 40 & 2.33 \\
Telecommunications Services & 40 & 2.33 \\
Machinery & 29 & 1.69 \\
Oil\&Gas & 29 & 1.69 \\
Electronics & 28 & 1.63 \\
Other Consumer Products & 28 & 1.63 \\
REITs & 23 & 1.34 \\
Food \& Beverage Retailing & 22 & 1.28 \\
Insurance & 22 & 1.28 \\
Other Retailing & 21 & 1.22 \\
Other Financials & 20 & 1.16 \\
Advertising \& Marketing & 19 & 1.11 \\
Building/Construction \& Engineering & 18 & 1.05 \\
Chemicals & 17 & 0.99 \\
Food \& Beverages & 17 & 0.99 \\
\hline
\end{tabular}


Table V

Dependent variable is recommendation coded from 1 (most optimistic), to 5 (less optimistic). Regression with robust standard errors Number of obs $=3614$

Number of clusters (analyst) $=1361$

\begin{tabular}{|c|c|c|c|c|}
\hline \multirow{3}{*}{ First } & $O L S$ & Ordered Logit & FixedEffects & RandomEffects \\
\hline & -.0603493 & -.2351518 & -.0589403 & -.0576215 \\
\hline & $(-1.75)^{*}$ & $(-1.80)^{*}$ & $(-1.75)^{*}$ & $(-1.95)^{* *}$ \\
\hline \multirow{2}{*}{ Dumins } & -.0175948 & -.0498783 & -.1152867 & -.078634 \\
\hline & $(-0.64)$ & $(-0.49)$ & $(-4.78)^{* * *}$ & $(-3.79)^{* * *}$ \\
\hline \multirow{2}{*}{ Numipo } & -.0000256 & -.0000923 & -.0000574 & -.0000312 \\
\hline & $(-0.78)$ & $(-0.76)$ & $(-1.76)^{*}$ & $(-1.10)$ \\
\hline \multirow{2}{*}{ Size } & .0000287 & .0001087 & -.0000553 & 0.00000268 \\
\hline & $(0.91)$ & $(0.91)$ & $(-1.60)$ & $(0.10)$ \\
\hline \multirow{2}{*}{ Six Month Return } & -.0097875 & -.0369763 & -.0190627 & -.0160713 \\
\hline & $(-0.70)$ & $(-0.71)$ & $(-1.56)$ & $(-1.42)$ \\
\hline \multirow{2}{*}{ S\&P 500 (E.W.I.) } & .0005639 & .001972 & .0004495 & .0005238 \\
\hline & $(1.78)^{*}$ & $(1.68)^{*}$ & $(1.50)$ & $(1.96)^{* *}$ \\
\hline Quarterly dummies & yes & yes & yes & yes \\
\hline Industry dummies & yes & yes & yes & yes \\
\hline Analyst fixed effects & no & no & yes & no \\
\hline R-. Squared & 0.0878 & 0.0559 & 0.0227 & 0.0766 \\
\hline
\end{tabular}

Note $: t-$ statistics in parenthesis:

$*$ significant at $10 \%, * *$ significant at $5 \%, * * *$ significant at $1 \%$

Hausman test for coefficient on first chi2 $=\frac{-.0013188}{.0163333}$ 
Table VI

Dependent variable is recommendation coded from 1 (most optimistic), to 5 (less optimistic).

Number of obs $=3614$

Regression with robust standard errors

Number of clusters (analyst) $=1361$

\begin{tabular}{|c|c|c|c|c|}
\hline \multirow{3}{*}{ Insstre } & $O L S$ & Ordered Logit & FixedEffects & RandomEffects \\
\hline & -.061897 & -.2457085 & -.043044 & -.0459819 \\
\hline & $(-1.93)^{*}$ & $(-2.03)^{* *}$ & $(-1.35)$ & $(-1.63)^{*}$ \\
\hline \multirow{2}{*}{ Dumins } & -.009928 & -.0179791 & -.1160697 & -.0775404 \\
\hline & $(-0.34)$ & $(-0.17)$ & $(-4.54)^{* * *}$ & $(-3.49)^{* * *}$ \\
\hline \multirow{2}{*}{ Numipo } & -.0000247 & -.0000881 & -.0000567 & -.0000304 \\
\hline & $(-0.75)$ & $(-0.73)$ & $(-1.74)^{*}$ & $(-1.07)$ \\
\hline \multirow{2}{*}{ Size } & .0000291 & .0001094 & -.0000547 & 0.00000329 \\
\hline & $(0.92)$ & $(0.91)$ & $(-1.58)$ & $(0.12)$ \\
\hline \multirow{2}{*}{ Six Month Return } & -.010271 & -.0385424 & -.0195319 & -.0165101 \\
\hline & $(-0.74)$ & $(-0.74)$ & $(-1.59)$ & $(-1.46)$ \\
\hline \multirow{2}{*}{ S\&P 500 (E.W.I.) } & .00056 & .0019566 & .0004465 & .0005215 \\
\hline & $(1.77)^{*}$ & $(1.67)^{*}$ & $(1.49)$ & $(1.95)^{* *}$ \\
\hline Quarterly dummies & yes & yes & yes & yes \\
\hline Industry dummies & yes & yes & yes & yes \\
\hline Analyst fixed effects & no & no & yes & no \\
\hline R Squared & 0.0880 & 0.0560 & 0.0226 & 0.0766 \\
\hline
\end{tabular}

Note $: t-$ statistics in parenthesis:

$*$ significant at $10 \%, * *$ significant at $5 \%, * * *$ significant at $1 \%$

Hausman test for insstre parameter $=\frac{.0029379}{.0148287}$ 
Table VII

Dependent variable is recommendation coded from 1 (most optimistic), to 5 (less optimistic). Regression with robust standard errors

Number of clusters (analyst) $=1361$

Number of obs $=3614$

\begin{tabular}{|c|c|c|c|c|}
\hline \multirow{3}{*}{ Onlyins } & $O L S$ & Ordered Logit & FixedEffects & RandomEffects \\
\hline & -.1382504 & -.548603 & -.0767929 & -.0940997 \\
\hline & $(-3.39)^{* * *}$ & $(-3.25)^{* * *}$ & $(-1.76)^{*}$ & $(-2.53)^{* *}$ \\
\hline \multirow{2}{*}{ Dumins } & -.0153119 & -.0418544 & -.122648 & -.0824697 \\
\hline & $(-0.60)$ & $(-0.44)$ & $(-5.48)^{* * *}$ & $(-4.32)^{* * *}$ \\
\hline \multirow{2}{*}{ Numipo } & -.0000257 & -.0000927 & -.0000564 & -.0000306 \\
\hline & $(-0.79)$ & $(-0.76)$ & $(-1.73)^{*}$ & $(-1.08)$ \\
\hline \multirow{2}{*}{ Size } & .0000261 & .0000991 & -.0000549 & 0.00000196 \\
\hline & $(0.83)$ & $(0.82)$ & $(-1.59)$ & $(0.07)$ \\
\hline \multirow{2}{*}{ Six Month Return } & -.0106935 & -.0402189 & -.019381 & -.0165915 \\
\hline & $(-0.77)$ & $(-0.77)$ & $(-1.58)$ & $(-1.47)$ \\
\hline \multirow{2}{*}{ S\&P 500 (E.W.I.) } & .0005684 & .0019893 & .0004472 & .0005279 \\
\hline & $(1.80)^{*}$ & $(1.70)^{*}$ & $(1.49)$ & $(1.98)^{* *}$ \\
\hline Quarterly dummies & yes & yes & yes & yes \\
\hline Industry dummies & yes & yes & yes & yes \\
\hline Analyst fixed effects & no & no & yes & no \\
\hline R Squared & 0.0898 & 0.0573 & 0.0233 & 0.0784 \\
\hline
\end{tabular}

Note : $t-$ statistics in parenthesis:

$*$ significant at $10 \%,{ }^{* *}$ significant at $5 \%, * * *$ significant at $1 \%$

Hausman test on parameter for onlyins $=\frac{.0173068}{.0226552}$ 
Table VIII dep-variable: is probability recommendation is the highest.

Number of observations:3614 for OLS, Fixed and Random Effects; 3602 for Probit.

Number of Clusters: 1361

\begin{tabular}{|lllll|}
\hline & OLS & Pr obit & FixedEffects & RandomEffects \\
First & .0573772 & .1597304 & .0581979 & .0555618 \\
& $(1.87)^{*}$ & $(1.95)^{* *}$ & $(2.03)^{* *}$ & $(2.20)^{* *}$ \\
Dumins & .0047433 & .0103156 & .0891007 & .061415 \\
& $(0.19)$ & $(0.16)$ & $(4.36)^{* * *}$ & $(3.46)^{* * *}$ \\
Numipo & .0000248 & .0000657 & .0000369 & .0000248 \\
& $(0.87)$ & $(0.88)$ & $(1.34)$ & $(1.02)$ \\
Size & 0.00000521 & .0000143 & .0000416 & .0000194 \\
& $(0.21)$ & $(0.21)$ & $(1.42)$ & $(0.84)$ \\
Six Month Return & .0079841 & .0214242 & .0166091 & .013844 \\
& $(0.62)$ & $(0.63)$ & $(1.60)$ & $(1.44)$ \\
S\&P 500 (E.W.I.) & -.0004563 & -.0012317 & -.0003174 & -.0003931 \\
Quarterly dummies & $(-1.60)$ & $(-1.64)^{*}$ & $(-1.25)$ & $(-1.73)^{*}$ \\
Industry dummies & $y e s$ & $y e s$ & $y e s$ & yes \\
Analyst fixed effects & no & yes & yes & yes \\
R Squared & 0.0827 & no & yes & no \\
\hline
\end{tabular}

Note: $t-$ statistics in parenthesis: ${ }^{*}$ significant at $10 \%,{ }^{* *}$ at $5 \%,{ }^{* * *}$ at $1 \%$

Hausman test for coefficient on first $=\frac{.0026361}{.0134663}$ 
Table IX - Logit estimation with analyst fixed effects.

Dep variable probability recommendation is highest.

Conditional fixed-effects logistic regression Number of obs $=1541$

Group variable (i): analyst, Number of groups $=307$

Obs per group: $\min =2 ;$ avg $=5.0 ; \max =32$

1054 groups (2073 obs) dropped due to all positive or all negative outcomes.

\begin{tabular}{|llll|}
\hline & primo & insstre & onlyins \\
Insalone & .5415884 & .464767 & .334733 \\
& $(2.04)^{* *}$ & $(1.85)^{*}$ & $(0.95)$ \\
Dumins & .8094513 & .795299 & .9352079 \\
& $(4.22)^{* * *}$ & $(3.96)^{* * *}$ & $(5.15)^{* * *}$ \\
Numipo & .0003488 & .0003356 & .0003581 \\
& $(1.25)$ & $(1.20)$ & $(1.28)$ \\
Size & .0004643 & .0004511 & .0004543 \\
& $(1.88)^{*}$ & $(1.83)^{*}$ & $(1.85)^{*}$ \\
Six Month Return & .16969 & .1719743 & .167388 \\
& $(1.90)^{*}$ & $(1.93)^{*}$ & $(1.88)^{*}$ \\
S\&P 500 (E.W.I.) & -.0011533 & -.001162 & -.0013269 \\
Quarterly dummies & $(-0.53)$ & $(-0.53)$ & $(-0.61)$ \\
Industry dummies & yes & yes & yes \\
Analyst fixed effects & yes & yes & yes \\
\hline Note: $z-$ statistics in & parenthesis: * significant at $10 \%,{ }^{* *}$ at $5 \%, * * *$ at $1 \%$
\end{tabular}


Regressions including the number of outsiders issuing a recommendation as a control

Table X

Dependent variable is recommendation coded from 1 (most optimistic), to 5 (less optimistic).

Number of obs $=1236$. R-squared $=0.1633$. Number of clusters (analyst) $=658$

(standard errors adjusted for clustering on analyst)

\begin{tabular}{|ll|}
\hline & recc \\
Number of outsiders & .0379669 \\
& $(1.91)^{*}$ \\
size & -.0001759 \\
& $(-1.94)^{*}$ \\
nu mipo & -.0000592 \\
& $(-1.15)$ \\
Six Month Return & -.0162068 \\
& $(-0.64)$ \\
S\&P 500 (E.W.I.) & .0016213 \\
& $(2.92)^{* * *}$ \\
quarterly dummies & yes \\
industry dummies & yes \\
\hline
\end{tabular}

Note: $t-$ statistics in parenthesis, ${ }^{*}:$ significant at $10 \%,{ }^{* *}$ at $5 \%,{ }^{* * *}$ at $1 \%$

Table XI

Dep variable probability recommendation is highest. Probit estimates.

Number of obs $=1213$. Pseudo R2 $=0.1199$

(standard errors adjusted for clustering on analyst)

\begin{tabular}{|ll|}
\hline & $\operatorname{Pr}($ recc $=1)$ \\
Number of outsiders & -.0969941 \\
& $(-1.98)^{* * *}$ \\
Size & .0004352 \\
& $(1.77)^{* *}$ \\
Nu mipo & .0002201 \\
& $(1.68)^{*}$ \\
Six Month Return & .0399261 \\
& $(0.64)$ \\
S\&P 500 (E.W.I.) & -.0046967 \\
& $(-3.57)^{* * *}$ \\
quarterly dummies & yes \\
industry dummies & yes \\
\hline
\end{tabular}

Note: $t$-statistics in parenthesis, ${ }^{*}:$ significant at $10 \%,{ }^{* *}$ at $5 \%,{ }^{* * *}$ at $1 \%$ 
Table XII-A - recommendation issued in the 3 days before the insider recommendation Dep variable probability recommendation is highest. Only recommendations from insiders. Probit estimates Number of obs $=125$

(standard errors adjusted for clustering on analyst)

\begin{tabular}{|lll|}
\hline & $\operatorname{Pr}($ recc $=1)$ & $\operatorname{Pr}($ recc $=1)$ \\
Outopt $($ avg $\leq 1.5)$ & .2755364 & \\
& $(1.15)$ & \\
Outopt $($ best $=1)$ & & .2512684 \\
& & $(1.05)$ \\
Size & .0004227 & .0004216 \\
& $(1.08)$ & $(1.08)$ \\
Nu mipo & .000161 & .000158 \\
& $(1.27)$ & $(1.25)$ \\
Six Month Return & .2282707 & .2305434 \\
& $(1.54)$ & $(1.55)$ \\
S\&P 500 (E.W.I.) & -.0027933 & -.0027537 \\
& $(-1.48)$ & $(-1.46)$ \\
\hline
\end{tabular}

Note: $z-$ statistics in parenthesis, ${ }^{*}$ : significant at $10 \%,{ }^{* *}$ at $5 \%,{ }^{* * *}$ at $1 \%$

TableXII-B All recommendation issued before the insider recommendation.

Dep variable probability recommendation is highest. Only recommendations from insiders. Probit estimates Number of obs $=257$

\begin{tabular}{|lll|}
\hline & $\operatorname{Pr}($ recc $=1)$ & $\operatorname{Pr}($ recc $=1)$ \\
Outopt $($ avg $\leq 1.5)$ & .1894889 & \\
& $(1.18)$ & \\
Outopt $($ best $=1)$ & & .1737748 \\
& & $(1.07)$ \\
Size & .0005006 & .0005001 \\
& $(1.67)^{*}$ & $(1.67)^{*}$ \\
Nu mipo & .0000777 & .0000765 \\
& $(0.87)$ & $(0.86)$ \\
Six Month Return & -.0376419 & -.0356409 \\
& $(-0.32)$ & $(-0.30)$ \\
S\&P 500 (E.W.I.) & -.0016543 & -.0016447 \\
& $(-1.25)$ & $(-1.25)$ \\
\hline
\end{tabular}

Note: $z$-statistics in parenthesis, ${ }^{*}$ : significant at $10 \%,{ }^{* *}$ at $5 \%,{ }^{* * *}$ at $1 \%$ 
Table XIII - Probability an outsider issues the best recommendation.

Dep variable probability recommendation is highest. Only recommendations from outsiders. Probit estimates Number of obs $=560$

(standard errors adjusted for clustering on analyst)

\begin{tabular}{|ll|}
\hline & Prob(Out $=1)$ \\
Insopt $($ recc $=1)$ & -.0856648 \\
& $(-0.63)$ \\
Size & -.0000118 \\
& $(-0.08)$ \\
Nu mipo & -.0001188 \\
& $(-1.95)^{* *}$ \\
Six Month Return & -.0263024 \\
& $(-0.37)$ \\
S\&P 500 (E.W.I.) & .000961 \\
& $(1.06)$ \\
\hline
\end{tabular}

Note: $z-$ statistics in parenthesis, ${ }^{*}$ : significant at $10 \%,{ }^{* *}$ at $5 \%, * * *$ at $1 \%$ 
Table XIV Heckman selection regression for the dummy insider faces less competition Dependent variable is recommendation coded from 1 (most optimistic), to 5 (less optimistic). Treatreg - Two Step

Number of Observations: 3788

Exclusion restriction on Size

\begin{tabular}{|c|c|c|c|}
\hline & first & insstre & onlyins \\
\hline Insalone & $\begin{array}{l}-.2415127 \\
(-1.46)\end{array}$ & $\begin{array}{l}-.3285428 \\
(-1.98)^{* * *}\end{array}$ & $\begin{array}{l}-.2160974 \\
(-1.45)\end{array}$ \\
\hline Dumins & $\begin{array}{l}-.0179517 \\
(-0.80)\end{array}$ & $\begin{array}{l}-.0097475 \\
(-0.40)\end{array}$ & $\begin{array}{l}-.0159332 \\
(-0.78)\end{array}$ \\
\hline Numipo & $\begin{array}{l}-.0000281 \\
(-0.87)\end{array}$ & $\begin{array}{l}-.0000236 \\
(-0.72)\end{array}$ & $\begin{array}{l}-.0000276 \\
(-0.86)\end{array}$ \\
\hline Six Month Return & $\begin{array}{l}-.0086122 \\
(-0.65)\end{array}$ & $\begin{array}{l}-.0108783 \\
(-0.81)\end{array}$ & $\begin{array}{l}-.0106999 \\
(-0.81)\end{array}$ \\
\hline S\&P 500 (E.W.I.) & $\begin{array}{l}.0005743 \\
(1.86)^{*}\end{array}$ & $\begin{array}{l}.0005596 \\
(1.79)^{*}\end{array}$ & $\begin{array}{l}.0005747 \\
(1.87)^{*}\end{array}$ \\
\hline Quarterly dummies & yes & yes & yes \\
\hline Industry dummies & yes & yes & yes \\
\hline \multirow[t]{2}{*}{$\begin{array}{l}\text { Covariance of } \\
\text { unobservables }\end{array}$} & $\begin{array}{l}.0994642 \\
(1.11) \\
\end{array}$ & $\begin{array}{l}1510167 \\
(1.63)\end{array}$ & $\begin{array}{l}.0415404 \\
(0.53)\end{array}$ \\
\hline & First & Stage & \\
\hline Size & $\begin{array}{l}.0016533 \\
(-5.30)^{* * *}\end{array}$ & $\begin{array}{l}-.0013702 \\
(-5.24)^{* * *}\end{array}$ & $\begin{array}{l}-.0073185 \\
(-6.53)^{* * *}\end{array}$ \\
\hline Numipo & $\begin{array}{l}.000000984 \\
(-0.01)\end{array}$ & $\begin{array}{l}.0000751 \\
(0.74)\end{array}$ & $\begin{array}{l}.0000186 \\
(0.14)\end{array}$ \\
\hline Six Month Return & $\begin{array}{l}.0301355 \\
(0.70)\end{array}$ & $\begin{array}{l}-.0157219 \\
(-0.38)\end{array}$ & $\begin{array}{l}-.070882 \\
(-1.04)\end{array}$ \\
\hline S\&P 500 (E.W.I.) & $\begin{array}{l}.0002399 \\
(0.23)\end{array}$ & $\begin{array}{l}-.0001515 \\
(-0.16)\end{array}$ & $\begin{array}{l}.0010675 \\
(0.71)\end{array}$ \\
\hline Quarterly dummies & yes & yes & yes \\
\hline Industry dummies & yes & yes & yes \\
\hline
\end{tabular}


Table XV Instrumental Variables regression.

Dependent variable is recommendation coded from 1 (most optimistic), to 5 (less optimistic).

First: IV (2SLS) regression with robust standard errors

Number of obs $=3413$ Number of clusters (analyst) $=1276$ R Squared $=0.0247$

Insstre: IV (2SLS) regression with robust standard errors

Number of obs $=3487$ Number of clusters (analyst) $=1305$ R Squared $=$.

onlyins: IV (2SLS) regression with robust standard errors

Number of obs $=3200$ Number of clusters (analysts) $=1191 \mathrm{R}$ Squared $=0.0652$

\begin{tabular}{|c|c|c|c|}
\hline \multirow{3}{*}{ Insalone } & first & insstre & onlyins \\
\hline & -.5701914 & -.6961021 & -.5205499 \\
\hline & $(-1.76)^{*}$ & $(-1.62)$ & $(-2.39)^{* *}$ \\
\hline \multirow{2}{*}{ Dumins } & .1678006 & .288949 & .070183 \\
\hline & $(1.43)$ & $(1.43)$ & $(1.51)$ \\
\hline \multirow{2}{*}{ Numipo } & -.0000789 & -.0000664 & -.000092 \\
\hline & $(-2.17)^{*}$ & $(-1.71)^{*}$ & $(-2.50)^{* *}$ \\
\hline \multirow{2}{*}{ Six Month Return } & .0000565 & -.0072089 & -.0041657 \\
\hline & $(0.00)$ & $(-0.48)$ & $(-0.29)$ \\
\hline \multirow{2}{*}{ S\&P 500 (E.W.I.) } & .0006208 & .0005925 & .0006075 \\
\hline & $(1.83)^{*}$ & $(1.76)^{*}$ & $(1.81)^{*}$ \\
\hline Quarterly dummies & yes & yes & yes \\
\hline \multirow[t]{2}{*}{ Industry dummies } & yes & yes & yes \\
\hline & First & Stage & \\
\hline \multirow{2}{*}{ Size } & -.0016533 & -.0013702 & -.0073185 \\
\hline & $(-5.30)^{* * *}$ & $(-5.24)^{* * *}$ & $(-6.53)^{* * *}$ \\
\hline \multirow{2}{*}{ Numipo } & -0.000000984 & .0000751 & .0000186 \\
\hline & $(-0.01)$ & $(0.74)$ & $(0.14)$ \\
\hline \multirow{2}{*}{ Six Month Return } & .0301355 & -.0157219 & -.070882 \\
\hline & $(0.70)$ & $(-0.38)$ & $(-1.04)$ \\
\hline \multirow{2}{*}{ S\&P 500 (E.W.I.) } & .0002399 & -.0001515 & -.0013702 \\
\hline & $(0.23)$ & $(-0.16)$ & $(-5.24)^{* * *}$ \\
\hline Quarterly dummies & yes & yes & yes \\
\hline Industry dummies & yes & yes & yes \\
\hline
\end{tabular}

2SLS: Get predicted probability of insalone. Then use the predicted probability from first stage as IV for insalone in a 2SLS regression. 